\title{
From past to future: suppressor mutations in yeast genes encoding translation termination factors
}

\author{
Nina Trubitsina ${ }^{1}$, Olga Zemlyanko ${ }^{1,2}$, Svetlana Moskalenko ${ }^{1,3}$, and \\ Galina Zhouravleva1,4 \\ ${ }^{1}$ Department of Genetics and Biotechnology, Faculty of Biology, Saint Petersburg State \\ University, Universitetskaya nab., 7-9, Saint Petersburg, 199034, Russian Federation \\ ${ }^{2}$ St. Petersburg Scientific Center, Russian Academy of Sciences, Universitetskaya nab., \\ 5, Saint Petersburg, 199034, Russian Federation \\ ${ }^{3}$ Vavilov Institute of General Genetics Russian Academy of Sciences, Saint Petersburg Branch, \\ Universitetskaya nab., 7-9, Saint Petersburg, 199034, Russian Federation \\ ${ }^{4}$ Laboratory of Amyloid Biology, Saint Petersburg State University, Botanicheskaya Str., \\ 17a, Peterhof, 198504, Russian Federation \\ Address correspondence and requests for materials to Galina Zhouravleva, \\ g.zhuravleva@spbu.ru
}

Citation: Trubitsina, N., Zemlyanko, J., Moskalenko, S., and Zhouravleva, G. 2019. From past to future: suppressor mutations in yeast genes encoding translation termination factors. Bio. Comm. 64(2): 89-109. https://doi.org/10.21638/ spbu03.2019.202

Author's information: Nina Trubitsina, PhD student, orcid.org/0000-0002-88928043; Olga Zemlyanko, Junior Researcher, orcid.org/0000-0003-3463-6675; Svetlana Moskalenko, PhD, Senior Researcher, orcid.org/0000-0003-0419-0000; Galina Zhouravleva, Dr. of Sci. in Biology, Professor Head of Department, orcid.org/0000-00023013-4662

Manuscript Editor: Alla Krasikova, Department of Cytology and Histology, Faculty of Biology, Saint Petersburg State University, Saint Petersburg, Russia

Received: May 6, 2019;

Revised: June 17, 2019;

Accepted: June 20, 2019;

Copyright: (c) 2019 Trubitsina et al. This is an open-access article distributed under the terms of the License Agreement with Saint Petersburg State University, which permits to the authors unrestricted distribution, and self-archiving free of charge.

Funding: This work was supported by grants from the Russian Science Foundation (Grant 18-14-00050) (parts 1-5) and the Russian Foundation for Basic Research (Grant 19-04-00173) (part 6: "Suppression due to prion $[\mathrm{PSI}+]^{\prime \prime}$ ); modelling of the 3D structure of eRF1-eRF3C-GDPNP protein complex with suppressor missense mutations was done in the frame of the State Research Program (0112-2016-0015).

\section{Abstract}

The study of the SUP45 and SUP35 genes of yeast Saccharomyces cerevisiae in the laboratory of Physiological Genetics of St. Petersburg State University began in 1964 when the first omnipotent nonsense suppressor mutations were obtained. During the following 55 years, a lot of information about these genes has been gained through the research efforts of various laboratories. Now we know that SUP45 and SUP35 encode translation termination factors eRF1 and eRF3, respectively. Both genes are essential, and sup45 and sup35 mutations lead not only to impaired translation but also to multiple pleiotropic effects. The aim of this review is to summarize known data about suppressor mutations in SUP45 or SUP35 genes.

Keywords: translation termination, suppression, SUP45, SUP35, eRF1, eRF3, nonsense mutations, missense mutations, $\left[P S{ }^{+}\right]$prion, S. cerevisiae.

\section{Introduction}

In eukaryotes, translation termination requires two eukaryotic release factors: eRF1 and eRF3. The eRF1 protein belongs to class 1 translation termination factors, responsible for the recognition of the stop codon and peptidyl-tRNA hydrolysis, and eRF3 - to class 2 termination factors, functioning to stimulate the work of class 1 factors due to its GTPase activity. Most eukaryotic organisms have a single class 1 translation termination factor called eRF1 (Frolova et al., 1994) that recognizes all three stop codons. In eukaryotic cells, class 2 translation termination factors are represented by eRF3 proteins (Stansfield et al., 1995a; Zhouravleva et al., 1995). Although all living organisms have a similar general translation termination mechanism, there are significant differences primarily between prokaryotes and eukaryotes (see review by Kisselev et al., 2003). During the last years several additional proteins participating in eukaryotic translation termination have been identified, including ABCE1 (Rli1 in S.cerevisiae), Dbp5, PABP, Hrp1, Pub1 and Upf proteins (see reviews by Tieg and Krebber, 2013; Schuller and Green, 2018).

It should be noted that the role of translation termination factors in the cell seems not to be limited to participation in translation termination, and these proteins are also likely to be involved in other stages of translation and different cellular processes. 
The main goal of this review is to summarize known data about suppressor mutations isolated in SUP35 or SUP45 genes with an emphasis on results obtained in the Department of Genetics and Biotechnology of St. Petersburg State University.

\section{The history of the discovery of the SUP45 and SUP35 genes}

The study of the SUP35 (SUP2) gene and functionally linked SUP45 (SUP1) gene in S.cerevisiae has a history of more than fifty years. In 1964, the mutations in these genes, named $s 1$ and $s 2$, recessive omnipotent nonsense suppressors, were obtained in the laboratory of Physiological Genetics of St. Petersburg State University (IngeVechtomov, 1964). The mutations in these genes caused the suppression of nonsense codons of all three types (Inge-Vechtomov and Andrianova, 1970), or omnipotent suppression. Developing a specific selection system for recessive suppressors promoted their further study. Haploid strains carrying the ade1-14 and his7-1 mutations (later identified as nonsense mutations UGA and UAA, respectively) were shown to revert to prototrophy mostly due to mutations in the genes $s 1$ and $s 2$ (IngeVechtomov and Andrianova, 1972). A similar phenomenon was found with simultaneous reversions to prototrophy for histidine and lysine in double mutants his71 (UAA) lys2-87 (UGA) (Inge-Vechtomov et al., 1988).

Later, similar omnipotent suppressor mutations were described in other laboratories: sup 35 u sup45 (Hawthorne and Leupold, 1974), supP and supQ (Gerlach, 1975). After that, by using the allelism test, it was shown that $\sup 1=\sup 45=\sup Q$, and $\sup 2=\sup 35=$ sup $P$ (see Sherman, 1982). When searching for genes affecting the translation fidelity, in the strain $\left[\mathrm{PSI}^{+}\right]$, the weak omnipotent suppressors sup 36 and sup 47 were isolated, that also turned out to be SUP35 и SUP45, alleles, respectively (Ono et al., 1984). Moreover, the GST1 gene (Kikuchi et al., 1988), a mutation in which led to the cell cycle block at the G1-S phase, also turned out to be identical to the SUP35 gene.

In the search for allosuppressor mutations that could increase the suppression efficiency of the weak dominant suppressor SUQ5, the SAL3 and SAL4 genes were found, which proved to be identical to the SUP35 and SUP45 genes (Crouzet and Tuite, 1987; Crouzet et al., 1988). Thus, various genetic approaches allowed identification of the genes, mutations in which led to recessive omnipotent suppression, allosuppression, cell cycle disorders, as well as numerous pleiotropic effects. These genes were commonly referred to as SUP45 (for sup1) and SUP35 (for sup2), with their identity being confirmed by their cloning and sequencing (Surguchev et al., 1983; Breining et al., 1984; Himmelfarb et al., 1985; Telkov et al., 1986; Breining and Piepersberg, 1986;
Crouzet and Tuite, 1987; Crouzet et al., 1988; Kushnirov et al., 1988; Wilson and Culbertson, 1988).

Genetic research data collected by the early 1990s led to a conclusion that the products of the SUP45 and SUP35 genes are involved in the control of translation fidelity, with this fact being confirmed by the analysis of biochemical data. In vitro ribosomes isolated from mutants sup 45 and sup 35 showed a high level of errors, with defective Sup45 and Sup35 proteins being associated with the $40 \mathrm{~S}$ subunit of the ribosome (Eustice et al., 1986). Later studies confirmed this and showed that Sup45 and Sup 35 proteins interact with monosomes and polysomes, this association being stronger than with the 40 S subunit (Didichenko et al., 1991; Stansfield et al., 1992).

The cloning and sequencing of the SUP45 and SUP35 genes showed that they encode proteins of 49 and $77 \mathrm{kDa}$, respectively (Himmelfarb et al., 1985; Breining and Piepersberg, 1986; Kushnirov et al., 1988; Wilson and Culbertson, 1988), their size exceeding the size of known ribosomal proteins. Moreover, the SUP45 gene was expressed at a rather low level, since SUP45 mRNA was only $1 / 10$ of the level of mRNA of the L3 ribosomal protein (Himmelfarb et al., 1985). While Sup45 protein did not reveal homology with any of the proteins known at that time (Breining and Piepersberg, 1986), the C-terminal domain of Sup35 protein was $37 \%$ identical to the yeast elongation factor eEF1-A (Kushnirov et al., 1988; Wilson and Culbertson, 1988). Taken together, these data suggest that Sup45 and Sup35 proteins may be translational factors closely associated with the small $40 \mathrm{~S}$ subunit of the ribosome (Himmelfarb et al., 1985; Kushnirov et al., 1988; Wilson and Culbertson, 1988).

The estimation of the relative content of Sup45 and Sup35 proteins over the ribosomal fraction showed that each of these proteins is present in a cell in a ratio of 1 to 20 ribosomes (Didichenko et al., 1991; Stansfield et al., 1992). Consequently, Sup 45 and Sup35 were more likely to be the factors of initiation or termination, rather than translation elongation, since the latter are usually present in equal stoichiometric ratios with the ribosomes (see review by Stansfield and Tuite, 1994).

The available biochemical data served as evidence for Sup45 and Sup35 proteins participating in the termination process, rather than translation initiation. Thus, even earlier studies proved a thermosensitive mutation in the SUP35 gene to cause the disruption of protein synthesis (Smirnov et al., 1974) and accumulation of 80 S ribosomes associated with peptidyl-tRNA (Smirnov et al., 1976). The identification of various types of tRNA complex allowed one to suggest that the defect under study was associated with translation termination but not translation initiation, as in the latter case, tRNA ${ }^{\text {Met }}$ would be the main component of the peptidyl-tRNA complex (Surguchov et al., 1980). The omnipotent sup- 
pressor phenotype of the sup 45 and sup 35 mutants also suggested defects in the translation termination process.

The deletion analysis of the corresponding gene provided further evidence of Sup35 protein involvement in termination. In the Sup35 protein, one can identify three domains bounded by methionines at 1,124 , and 254 amino acid (aa) positions (Figure 1A). These domains differ in a number of properties. The $\mathrm{N}$-terminal domain (aa 1-123) is enriched in $\mathrm{Q}$ and $\mathrm{N}$ residues and contains oligopeptide repeats. The M-domain (aa 124253 ) is enriched with charged amino acid residues. The C-terminal domain (aa 254-685) reveals homology with the elongation factor eEF1-A. The SUP35 gene (similar to the SUP45 gene) is an essential gene (see below). The presence of only the C-terminal domain in the cell proved to be sufficient to compensate for the deletion of this gene. At the same time, the TEF1 gene, encoding eEF1-A, could not compensate for the deletion of the SUP35 gene, indicating the difference in the functions of eEF1-A and Sup35 proteins during the translation process. An increase in the content of the C-terminal domain in the cell led to anti-suppression (Ter-Avanesyan et al., 1993), while the over-expression of the full-length SUP35 gene (or its $\mathrm{N}$-terminal domain) caused omnipotent suppression (Chernoff et al., 1988; Chernoff et al., 1993; Ter-Avanesyan et al., 1993; Derkatch et al., 1996). Later, the prion hypothesis enabled these results to be explained.

By the beginning of the 1990s, in yeast, two cytoplasmic allosuppressors were found, identified as $\left[\mathrm{PSI}^{+}\right]$ (Cox, 1965) and $\left[\mathrm{ETA}^{+}\right]$(Liebman and All-Robyn, 1984). The $\left[\mathrm{PSI}^{+}\right]$factor increased the suppression of weak tRNA suppressors, such as SUQ5 (Cox, 1965) and resulted in lethality in combination with SUP11-o and SUP3-o (Cox, 1971). The $\left[E T A^{+}\right]$factor, in turn, resulted in lethality in combination with sup35-2 and sup452 mutations but did not affect the viability of the other sup35 and sup45 mutants under study (Liebman and All-Robyn, 1984; All-Robyn et al., 1990). Later, $\left[P S I^{+}\right]$ and $\left[E T A^{+}\right]$were shown to be different forms of the same factor $\left[\mathrm{PSI}^{+}\right]$(Zhou et al., 1999). For a long time, the molecular nature of this factor remained inexplicable until it was shown that the $\left[\mathrm{PSI}^{+}\right]$factor is a product of the SUP35 gene (Chernoff et al., 1993; Doel et al., 1994; TerAvanesyan et al., 1994). Not long after that, R. Wikner suggested that Sup35 protein might be a yeast prion (Wickner, 1994).

Thus, by the beginning of the 1990s, the exact role of Sup 45 and Sup35 proteins in translation remained unidentified. Although in early works, Sup 45 and Sup35 proteins were supposed to be involved in translation termination (Inge-Vechtomov and Andrianova, 1970), the lack of homology with prokaryotic release factors (RF), as well as the absence of an anti-suppressor effect during overexpression did not allow them to be considered as translation factors (see Stansfield and Tuite, 1994). It was assumed that these proteins could play a supporting role in translation termination by interacting with release factors or with ribosomes. While prokaryotic translation release factors were first characterized a long time ago (Craigen et al., 1985; Craigen and Caskey, 1987), the eukaryotic termination factors remained unidentified for a long time. The cloning of cDNA encoding the RF of a rabbit was reported in 1990 (Lee et al., 1990). A surprisingly high degree of similarity between the protein and tryptophanyl-tRNA synthetase identified served as evidence that the identified gene encodes the rabbit tryptophanyl synthetase but not the RF factor (Frolova et al., 1993). Even in early experiments, translation termination in mammals was demonstrated to be a GTP-dependent process (Beaudet and Caskey, 1971; Konecki et al., 1977), but to isolate a protein with GTPase activity was not possible.

In 1994, the laboratory of L.L. Kiselev in collaboration with some foreign laboratories found Sup 45 protein to be a termination factor capable of recognizing stop codons (Frolova et al., 1994). Due to this property, it was named eRF1 and, together with the bacterial proteins RF1 and RF2, was assigned to class 1 termination factors. The following year, data was obtained that was significant to establish the role of Sup35 protein as a second termination factor; it was named eRF3 because its functions are analogous to the bacterial RF3 (Zhouravleva et al., 1995).

\section{Molecular mechanism of the translation termination process in eukaryotes}

In eukaryotes, for efficient translation termination, it is necessary that eRF1 should interact directly with eRF3 in the presence of GTP (Stansfield et al., 1995a; Zhouravleva et al., 1995; Frolova et al., 1996). It was shown that the interaction of the yeast eRF1 and eRF3 is possible only if eRF3 is associated with GTP (Kobayashi et al., 2004). This interaction is supposed to lead to conformational changes that allow eRF1 to interact efficiently with the stop codon in the A-site of the ribosome. Conformational rearrangements seem to be necessary for the exact correspondence of the distance between the GGQ motif and the "protein anticodon" in eRF1 ( $80 \AA)$ and the distance between the peptidyl-transferase center of the ribosome and the stop codon $(75 \AA)$. However, the binding of the termination factors to the ribosome is not enough to effectively terminate translation. Additional conformational changes in the structure of $\mathrm{eRF} 1$ are required to correctly orient the GGQ motif in the peptidyl transferase center (Alkalaeva et al., 2006). The energy for such a rearrangement is provided by the hydrolysis of GTP by the eRF3. The eRF3 associated with GDP dissociates from eRF1 (Kobayashi et al., 2004). Given the above, the role of the eRF3 in transla- 
A

GTP

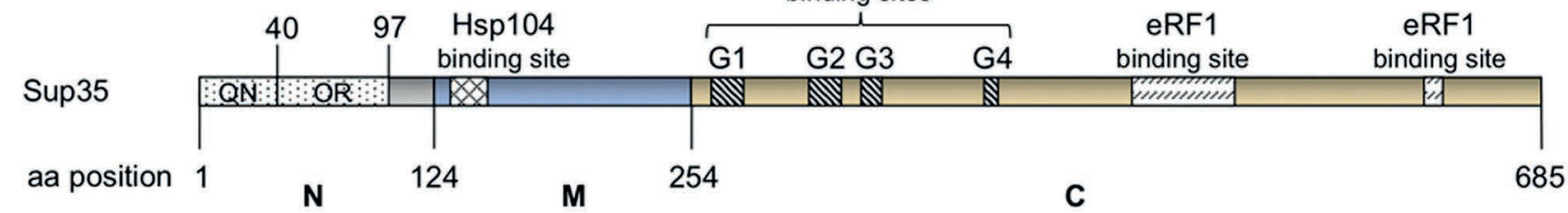

B

Prion domain Charged domain

eEF1A-like domain

213

$\sup 35$

Sup35

PTC position

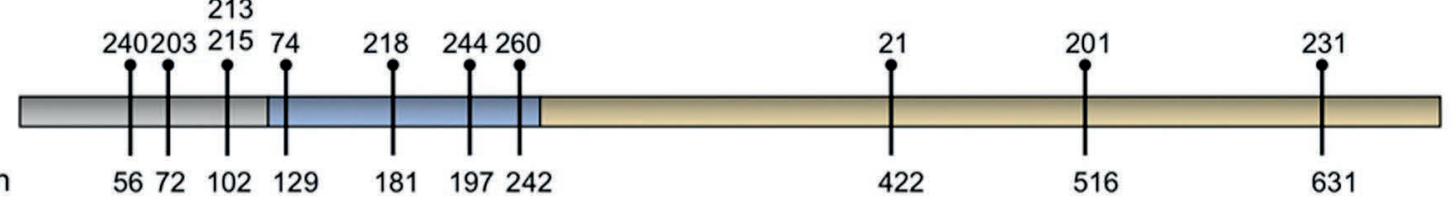

C

YSUP35 MFGGKDHVSLIFMGHVDAGKSTMGGNLLYLTGSVDKRTIEKYEREAKDAGROGWYLSWVMDTNKEERNDGKTIEVGKAYFETERRRYTILDAPGHKMYVS 353 hGSPT1 ---KKEHVNVVF IGHVDAGKSTIGGQIMYLTGMVDKRTLEKYEREAKEKNRETWYLSWALDTNQEERDKGKTVEVGRAYFETEKKHFTILDAPGHKSFVP

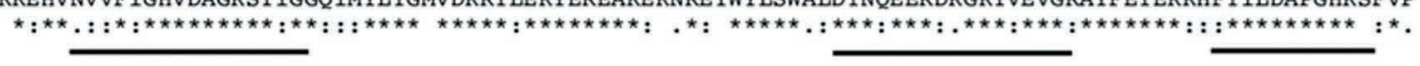

G1

G2

G3

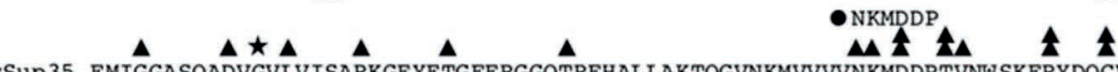

ySUP35 EMIGGASQADVGVLVISARKGEYETGFERGGQTREHALLAKTQGVNKMVVVVNKMDDPTVNWSKERYDQCVSNVSNFLRAIGYNIKTDVVFMPVSGYSGA 453

hGSPT1 NMIGGASQADLAVLVISARKGEFETGFEKGGQTREHAMLAKTAGVKHLIVLINKMDDPTVNWSNERYEECKEKLVPFLKKVGFNPKKDIHFMPCSGLTGA

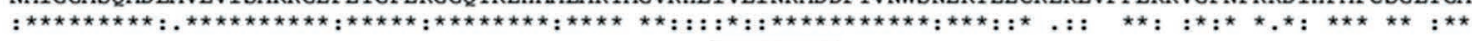

G4

ySUP35 NLKDHVDPKECPWYTGPTLLEYLDTMNHVDRHINAPFMLPIAAKMKDLGTIVEGKIESGHIKKGQSTLLMPNKTAVEIQNIYNETENEVDMAMCGEQVKL 553 hGSPT1 NLKEQSD--FCPWY IGLPF IPYLDNLPNFNRSVDGPIRLPIVDKYKDMGTVVLGKLESGS ICKGQQLVMMPNKHNVEVLGILSD-DVETDTVAPGENLKI

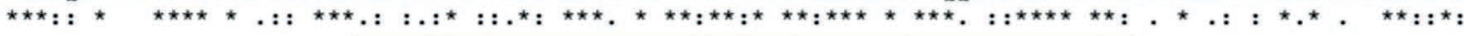

eRF1

ySUP35 RIKGVEEEDISPGFVLTSPKNPIKSVTKFVAQIAIVELKSIIAAGFSCVMHVHTAIEEVHIVKLLHKLEKGTNRKSKKPPAFAKKGMKVIAVLETEAPVC $\underset{\text { 653 }}{\boldsymbol{\Delta}}$ hGSPT 1 RLKGIEEEEILPGF ILCDPNNLCHSGRTFDAQIVIIEHKS IICPGYNAVLH IHTCIEEVEITALICLVDKKSGEKSKTRPRFVKQDQVCIARLRTAGT IC

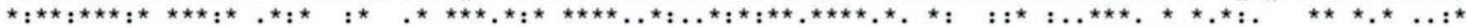

eRF 1

ySUP35 VETYQDYPQLGRFTLRDQGTTIAIGKIVKIAE--- 685

hGSPT 1 LETFKDFPQMGRFTLRDEGKTIAIGKVLKLVPEKD

$: \star \star:: \star: \star \star: \star \star \star \star \star \star \star *: * * \star \star \star \star * \star:: *:$.

Fig. 1. The mutations obtained in the SUP35 gene.

A. Sup35p consists of three domains: N, M and C, which were assigned by positions of three ATG codons in the SUP35 sequence (Kushnirov et al., 1988). N-domain includes two regions: QN-rich and oligopeptide repeats (OR), which are needed for [PSI+ $]$ formation and propagation. M-domain is enriched with charged aa and contains the site for Hsp104 chaperon binding (Helsen and Glover, 2012). Together $\mathrm{N}$ and $\mathrm{M}$ domains are involved in prion forming domain of Sup35p (PFD). Essential C-domain containing GTP (Kushnirov et al., 1987; Hoshino et al., 1998) and eRF1 (Paushkin et al., 1997; Ito et al., 1998; Ebihara and Nakamura, 1999; Merkulova et al., 1999) binding sites perform main functional role of Sup35 as translation termination factor eRF3. C-domain shows homology with elongation factor eEF-1A and EF-Tu (Kushnirov et al., 1987; Kong et al., 2004). B. Nonsense mutations in SUP35 gene obtained in our laboratory (Chabelskaya et al., 2004). Numbers above Sup35 protein scheme correspond to numbers of sup35 mutations. PTC (premature termination codon) positions match to the aa length of truncated proteins formed in the case of translation termination on the sup35 mutation. C. Missense mutations in SUP35 gene obtained in different laboratories (Volkov et al., 2002; 2007; Bradley et al., 2003; Chabelskaya et al., 2004; Kobayashi et al., 2004; Salas-Marco and Bedwell, 2004; Fabret et al., 2008 and our unpublished data). Alignment of S. cerevisiae Sup35 and $H$. sapiens GSPT1 C-domains is shown. The triangle sign - single missense mutations (stacks of them correspond to hotspot mutation sites). The star sign shows double mutation G365V/E559K (Chabelskaya et al., 2004). Underlined six aa and the circle sign mean six aa duplication (Chabelskaya et al., 2004). GTP and eRF1 binding sites are underlined. 
tion termination was supposed to be reduced to a change in the conformational states of eRF1 (Alkalaeva et al., 2006; Fan-Minogue et al., 2008).

A distinctive feature of eRF3 is its ability to form a stable complex with eRF1 (Stansfield et al., 1995a; Zhouravleva et al., 1995; Frolova et al., 1998) due to the interaction between the C-terminal domains of both factors (Ito et al., 1998; Ebihara and Nakamura, 1999; Merkulova et al., 1999). It was assumed that eRF3 might play a role similar to bacterial RF3 by providing "recycling" (Zavialov et al., 2001). However, according to genetic data, the eRF3 GTPase activity is needed both to ensure correct recognition of stop codons by the eRF1 and for subsequent release of the newly synthesized peptide (Salas-Marco and Bedwell, 2004). Taken together, the above data, as well as the translation termination simulation in vitro, made it possible to modify the existing translation termination model (Alkalaeva et al., 2006). eRF3 is believed to bind to the ribosome in the presence of GTP, and the subsequent hydrolysis of GTP is necessary for eRF1 to be able to induce the release of the newly synthesized polypeptide. The model given is consistent with the results of the crystal structure characteristics of the eRF3 (aa 196-662) C-terminal domain of Schizosaccharomyces pombe (Kong et al., 2004). Functional differences between eRF3 and RF3 may be due not only to their different origins but also to only one class 1 termination factor being present in eukaryotes, that should not only recognize the stop codons UAG, UAA, and UGA but also distinguish them from similar codons, especially the UGG codon (see reviews by Ehrenberg and Tenson, 2002; Kisselev et al., 2003; Nakamura and Ito, 2003). Such features of eukaryotic translation termination could require an additional step provided by eRF3.

\section{Termination factor eRF3}

\subsection{STRUCTURE OF YEAST ERF3}

The eRF3 proteins of most eukaryotes, except for some protozoa, have a three-domain structure (see review by Inge-Vechtomov et al., 2003). In S. cerevisiae, the eRF3 is encoded by the SUP35 gene (Zhouravleva et al., 1995), which is an essential gene (Wilson and Culbertson, 1988; Grentzmann et al., 1994; Mikuni et al., 1994). The $\mathrm{N}$-domain of yeast Sup35 was shown not to be necessary for the viability of the cell (Ter-Avanesyan et al., 1993). Interestingly, this domain (named also PFD prion-forming domain) is responsible for the possibility of Sup35 prionization with the formation of the $\left[\mathrm{PSI}^{+}\right]$ determinant (Ter-Avanesyan et al., 1994; Derkatch et al., 1996; Paushkin et al., 1996). In the N-domain, two regions may be identified: a region rich in $\mathrm{Q}$ and $\mathrm{N}$ (within 1-40 amino acid residues) and a region of oligopeptide repeats (amino acid residues 41-97) containing five full
PQGGYQ(Q)QYN repeats from nine amino acids and one partial repeat, containing four amino acids PQGG (Kushnirov et al., 1988) (Fig. 1A). The $\mathrm{N}$-domain of the eRF3 family proteins is highly variable, with its amino acid sequence differing even in closely related species.

The Sup35 M-domain is enriched with charged amino acids and is involved in maintaining prion in a series of cell divisions. A short section from 129-148 aa is involved in the interaction with $\mathrm{Hsp} 104$ and stimulates the ability of the chaperone to break down $\left[\mathrm{PSI}^{+}\right]$ fibrils. Despite N- and M-domains being nonessential for Sup35 activity, their conservation suggests them to be a two-component functional unit, the critical role of which remains still unexplored. NM-domain forms reversible $\mathrm{pH}$ dependent biomolecular condensates (Franzmann et al., 2018).

The C-terminal domain of the Sup35 protein is necessary and sufficient to participate in translation termination (Ter-Avanesyan et al., 1993). It contains GTPbinding domains (Kushnirov et al., 1987; Hoshino et al., 1998) and an eRF1-binding site (Paushkin et al., 1997; Ito et al., 1998; Ebihara and Nakamura, 1999; Merkulova et al., 1999).

\subsection{SUPPRESSOR MUTATIONS IN THE SUP35 GENE}

A dysfunction of Sup35 may account for a suppressor effect. Therefore, studying suppressor mutations may provide insight into the role of Sup35 in the translation termination process. When selecting mutations in the SUP35 gene by simultaneous reversion of the ade1-14 (TGA) and his7-1 (TAA) mutations, 48 sup35 mutations were obtained (Chabelskaya et al., 2004). After analyzing the content of Sup35 protein in these mutants, it was shown that in 32 of them, the amount of Sup35 did not differ from the strain carrying the wild-type SUP35 allele, while a third of the strains (16 mutants) had a lower content of Sup35 protein compared with the original strain. 15 mutants were selected to be sequenced, with five having the same level of the full-length Sup35 protein as in the wild type and 10 revealing a reduced amount of the full-length Sup35 protein (Chabelskaya et al., 2004) (Table 1 and Fig. 1B, C). The molecular nature of these mutations and their comparison with those described in the literature is discussed in the following sections.

\subsubsection{Nonsense mutations in the SUP35 gene}

Among ten sup35 nonsense mutations characterized, seven are localized in the first third of the SUP35 gene, encoding the NM-domain of eRF3 (aa 1-253) (Fig. 1B). Such an uneven distribution of nonsense mutations can be accounted for by an increased codon content, with a single substitution capable of resulting in a stop codon. 
Table 1. The mutations in the SUP35 gene, described in different works.

$X$ means substitution of amino acid to stop codon; $t$ indicates the lethality of mutation

\begin{tabular}{|c|c|c|c|c|}
\hline Method of selection & $\begin{array}{l}\text { Type of } \\
\text { mutation }\end{array}$ & Nucleotide changes & Amino acid changes & Reference \\
\hline $\begin{array}{l}\text { UV-mutagenesis (strain SL183- } \\
\text { 21C) }\end{array}$ & Nonsense & T229A & L110X & Zhou et al., 1999 \\
\hline $\begin{array}{l}\text { Suppression of his7-1(UAA) and } \\
\text { trp1-289 (UAG) (strain 33G-D373) }\end{array}$ & Nonsense & C1264T & Q422X & $\begin{array}{l}\text { Cosson et al., } \\
2002\end{array}$ \\
\hline $\begin{array}{l}\text { Suppression of ade1-14(UGA) his7- } \\
\text { 1(UAA) and lys2-87 (UGA) (strain } \\
2 \text { V-P3982) }\end{array}$ & Missense & $\begin{array}{l}\text { G1087A; C1133T; G1237A; } \\
\text { C1724A }\end{array}$ & D363N; T378I; V413L; P575H & $\begin{array}{l}\text { Volkov et al., } \\
2002\end{array}$ \\
\hline \multirow{2}{*}{$\begin{array}{l}\text { Suppression of ade1-14 (UGA) } \\
\text { (strain 74-D694) }\end{array}$} & Missense & $\begin{array}{l}\text { G959T; A1052G; G1070A; } \\
\text { G1256A; G1429T; A1607C; } \\
\text { T1957C }\end{array}$ & $\begin{array}{l}\text { R320I; Y351C; G357D; R419H; D477Y; } \\
\text { N536T; C653R }\end{array}$ & \multirow[t]{2}{*}{$\begin{array}{l}\text { Bradley et al., } \\
2003\end{array}$} \\
\hline & Nonsense & $\begin{array}{l}\text { C64T; C147G; C211T; C214T; } \\
\text { G229T; G334T; G514T (two } \\
\text { times); G553T; C629A; C668G; } \\
\text { G1609 }\end{array}$ & $\begin{array}{l}\text { Q22X; Y49X; Q71X; Q72X; G77X; } \\
\text { G112X; E172X (two times); E185X; } \\
\text { S210X; S223X, E537X }\end{array}$ & \\
\hline \multirow{4}{*}{$\begin{array}{l}\text { Suppression of ade1-14(UGA) and } \\
\text { his7-1(UAA) (strain 1B-D1606) }\end{array}$} & Missense & $\begin{array}{l}\text { C1115T; G1697A; G1808T; } \\
\text { G1094T/G1675A; }\end{array}$ & $\begin{array}{l}\text { R372K; G566N; M603K; G365V/ } \\
\text { E559K }\end{array}$ & \multirow[t]{3}{*}{$\begin{array}{l}\text { Chabelskaya et } \\
\text { al., } 2004\end{array}$} \\
\hline & Nonsense & $\begin{array}{l}\text { C166T; C214T; A304T(two times); } \\
\text { C388T; G541T; G586T; C724T; } \\
\text { C1264T; A1546T; C1984T }\end{array}$ & $\begin{array}{l}\text { Q56X; Q72X; K102X (two times); } \\
\text { Q129X; E181X; E197X; Q242X; } \\
\text { Q422X; K516X; Q631X }\end{array}$ & \\
\hline & Duplication & $\begin{array}{l}18 \text { bp duplication (begins at } \\
\text { nucleotide 1217) }\end{array}$ & additional 6 aa (begins at aa 305) & \\
\hline & $\begin{array}{l}\text { Mutation in } \\
\text { promoter }\end{array}$ & $\mathrm{G}(-183) \mathrm{T}$ & no & $\begin{array}{l}\text { Matveenko et al., } \\
2019\end{array}$ \\
\hline \multirow{2}{*}{$\begin{array}{l}\text { Suppression of lys9-A21 (UAA) and } \\
\text { his7-1(UAA) (strain 33G-D373) }\end{array}$} & Missense & A1234C; G1939A & T412P; E647K & \multirow{2}{*}{$\begin{array}{l}\text { Our unpublished } \\
\text { data }\end{array}$} \\
\hline & Nonsense & C388T & Q129X & \\
\hline Site directed mutagenesis & Missense & $\begin{array}{l}\text { T806G; A1043T; U/C1044G/A; } \\
\text { A1999G; GAU1225UGG; A1255G }\end{array}$ & $\begin{array}{l}\text { V269Gt; H348Lt; H348Q; K407Et; } \\
\text { D409Wt; R419G }\end{array}$ & $\begin{array}{l}\text { Salas-Marco and } \\
\text { Bedwell, } 2004\end{array}$ \\
\hline PCR mutagenesis & Missense & A1219T; G1227A & N406l; D409N & $\begin{array}{l}\text { Kobayashi et al., } \\
2004\end{array}$ \\
\hline $\begin{array}{l}\text { Suppression of ade1-14(UGA) his7- } \\
\text { 1(UAA) (strain SUP35C-2V-P3982) }\end{array}$ & Missense & $\begin{array}{l}\text { C1157T; G1268A (two times); } \\
\text { C1724A }\end{array}$ & T386l; C423Y (two times); P575H & \multirow[t]{2}{*}{$\begin{array}{l}\text { Volkov et al., } \\
2007\end{array}$} \\
\hline $\begin{array}{l}\text { Suppression of ade1-14(UGA) his7- } \\
\text { 1(UAA) (strain pRSU1C-16AD1608) }\end{array}$ & Missense & $\begin{array}{l}\text { T1018C; T1100C; C1235T/ } \\
\text { C1236T }\end{array}$ & Y340H; L367S; T412I & \\
\hline Site directed mutagenesis & Missense & A1021G; AC1021GA & T341A; T341D† & $\begin{array}{l}\text { Fabret et al., } \\
2008\end{array}$ \\
\hline
\end{tabular}

The SUP35 gene region encoding the NM-domain does contain $48 \%$ of such codons compared with $33 \%$ in the region encoding the $\mathrm{C}$-domain of eRF3 and with $34 \%$ in the entire yeast genome (Table 2). The absence of mutations resulting in the TGA stop codon among the sup35$n$ mutations can be explained by the reduced content of "potential" UGA codons (codons, single mutations which can lead to the appearance of the UGA codon). The SUP35 gene sequence does contain $10 \%$ of such codons, compared with $39 \%$ and $51 \%$ for potential codons UAG and UAA, respectively (Table 2). These data correlate with the number of isolated mutations containing TAG (4 mutations) and TAA (6 mutations) (Table 3).
It is worth noting that in the screening for $\mathrm{Ade}^{+}$revertants twelve sup35- $n$ mutations were isolated, with six being TAG mutations and the rest evenly distributed between TAA and TGA mutations (Bradley et al., 2003). The differences in the ratios of the types of sup35- $n$ mutations can be explained by the differences in the mutant selection methods.

\subsubsection{Missense mutations in the SUP35 gene}

The finding that all missense mutations isolated from different strains are localized in the C-terminal domain of eRF3 (aa 254-685) (Fig. 1C, Fig. 2 and Table 1) con- 
Table 2. The distribution of potential stop codons in the SUP35 and SUP45 genes. The program "Countcodon" (http://www.kazusa.or.jp/codon / countcodon.html) was used to calculate the content of different codons

\begin{tabular}{|c|c|c|c|c|c|}
\hline \multirow{2}{*}{ Gene } & \multirow{2}{*}{$\begin{array}{l}\text { Domain } \\
\text { (codons } \\
\text { number) }\end{array}$} & \multicolumn{4}{|c|}{$\begin{array}{l}\text { The number of potential stop } \\
\text { codons (\%): }\end{array}$} \\
\hline & & UAA & UAG & UGA & All \\
\hline \multirow[t]{5}{*}{ SUP35 } & N (123) & 29.7 & 17.9 & 3.6 & 51.2 \\
\hline & M (139) & 22.6 & 21.6 & 0.4 & 44.6 \\
\hline & C (433) & 16.2 & 12.1 & 4.7 & 33.0 \\
\hline & N+M (252) & 26.1 & 20.1 & 2.0 & 48.2 \\
\hline & $N+M+C(685)$ & $\begin{array}{c}19.8 \\
(51 \%)\end{array}$ & $\begin{array}{c}15.1 \\
(39 \%)\end{array}$ & $\begin{array}{c}3.7 \\
(10 \%)\end{array}$ & $\begin{array}{c}38.6 \\
(100 \%)\end{array}$ \\
\hline \multirow[t]{4}{*}{ SUP45 } & N (132) & 19.9 & 14.2 & 4.8 & 39.1 \\
\hline & M (120) & 14.2 & 8.7 & 7.9 & 30.8 \\
\hline & C (185) & 22.7 & 12.4 & 3.2 & 38.3 \\
\hline & $N+M+C(437)$ & $\begin{array}{c}19.7 \\
(53 \%)\end{array}$ & $\begin{array}{c}12.0 \\
(33 \%)\end{array}$ & $\begin{array}{c}5.2 \\
(14 \%)\end{array}$ & $\begin{array}{c}36.9 \\
(100 \%)\end{array}$ \\
\hline $\begin{array}{l}\text { Total in the genome } \\
\text { of S. cerevisiae }\end{array}$ & & $\begin{array}{c}14.5 \\
(43 \%)\end{array}$ & $\begin{array}{c}12.5 \\
(37 \%)\end{array}$ & $\begin{array}{c}7.1 \\
(20 \%)\end{array}$ & $\begin{array}{c}34.1 \\
(100 \%)\end{array}$ \\
\hline
\end{tabular}

Table 3. Nucleotide context surrounding sup45 and sup35 nonsense mutations

\begin{tabular}{l|l|l}
\hline \multicolumn{1}{c|}{ Mutation } & $\begin{array}{c}\text { Amino } \\
\text { acid } \\
\text { position }\end{array}$ & \multicolumn{1}{c}{$\begin{array}{c}\text { Nucleotide context surrounding } \\
\text { preliminary termination codon*: } \\
\text { 5' stop } 3^{\prime}\end{array}$} \\
\hline sup45-102 & Y53 & TTA ACA GAT GAA TAA GGT ACT GCC TCG \\
\hline sup45-101, 20 & E266 & AAC CAG GCT ATC TAA CTT TCT GCC GAA \\
\hline sup45-104 & L283 & CAA GAA AAG AAA TAA TTG GAG GCA TAT \\
\hline sup45-13 & E266 & GCT ACC GGC CAA TAA ATG GAC GTT GTC \\
\hline sup35-240 & Q56 & GGT TCT GGG TAC TAA CAA GGT GGC CAA \\
\hline sup35-218 & E181 & GCT GAA ACC AAA TAA CCA ACT AAA GAG \\
\hline sup35-13, 215 & K102 & CGT GGA AAT TAC TAA AAC TTC AAC TAC \\
\hline sup35-231 & Q631 & CAA GAT TAC CCT TAA TTA GGT AGA TTC \\
\hline sup35-21 & Q422 & GAA CGT TAC GAC TAA TGT GTG AGT AAT \\
\hline sup35-74 & Q129 & TTG AAC GAC TTT TAA AAG CAA CAA AAG \\
\hline sup35-201 & K516 & GGT CAT ATC AAA TAG GGT CAA TCC ACC \\
\hline sup35-260 & Q242 & TTG ATC AAG GAA TAG GAA GAA GAA GTG \\
\hline sup35-244 & E197 & CCA GTT AAA AAG TAG GAG AAA CCA GTC \\
\hline sup35-203 & Q72 & GGT TAC CAG CAA TAG TAT AAT CCT CAA \\
\hline sup45-107 & L317 & GCA GTC GAA AAA TGA ATT GTT TTC GAA \\
\hline
\end{tabular}

* CAA codons are underlined, adenines preceding nonsense mutations and promoting the translation of stop codons in yeast cells (Tork et al., 2004) are highlighted in yellow. Nucleotides at position +4 , contributing to and inhibiting the translation of the stop codon (Bonetti et al., 1995) are highlighted in blue and green, respectively. firms numerous data on the role of this domain in translation termination.

The suppressor phenotype of isolated missense mutations cannot be explained by a reduced amount of eRF3 or the inability of mutant eRF3 to interact with eRF1. These mutations may affect the interaction of eRF3 with other proteins or the ribosome.

All missense mutations obtained result in amino acid substitutions that are conservative between S.cerevisiae and S. pombe eRF3. The exception was one of the substitutions in the case of the double sup35-233 mutation (G365V; E559K): $\mathrm{N}$ residue was substituted for $\mathrm{E}$ residue in the S. pombe eRF3 in the homologous position, making it possible to arrange the corresponding amino acid substitutions in the tertiary structure of the C-terminal domain of S. pombe eRF3 (Kong et al., 2004).

The sup35-228 mutation results in arginine being replaced with lysine at position 372 . While being very similar chemically, these two amino acids differ in their methylation capacity. A number of studies have shown a simple replacement of arginine with methylated lysine to result in a defective protein, with developmental disorders of transgenic tobacco plants as a result of a mutation in the calmodulin gene (Roberts et al., 1992) and a sharp decrease in RNase activity in the case of human mutant angiogenin (Shapiro et al., 1989).

It should be noted that about half of the sup $35 \mathrm{mu}$ tations reported in the works of different authors are located either in the SUP35 regions encoding the GTPase domains of eRF3 or in the immediate vicinity of these sites (Fig. 1C, Table 1). Interestingly, the phenotypic manifestation of mutations located in the C-terminal domain of eRF3 may be influenced by the presence of the N-terminal domain of eRF3 (Volkov et al., 2007). The same mutations obtained on the background of a full-sized or truncated SUP35 had a different phenotypic manifestation (Volkov et al., 2007). The interaction of this site with the mutant $\mathrm{C}$-terminal domain may reduce the GTPase activity of eRF3, resulting in the suppression efficiency increase.

The nature of the suppression was investigated in details in two mutants in the GTPase domain of yeast eRF3 (Salas-Marco and Bedwell, 2004), by studying the mutants of eRF3 with impaired hydrolysis of GTP.If the functions of eRF3 coincide with those of RF3, the eRF3 mutations leading to the nucleotide exchange rate decrease should also slow down the release of eRF1 from the termination complex. This, in turn, should lead to a decrease in the pool of eRF1 available for subsequent termination events. At the same time, mutations that damage the GTP hydrolysis rate should be defective in the dissociation of eRF3 from the ribosomes. In this case, the pool of free eRF3 should decrease, thus decreasing eRF1 recycling. In the work concerned, six sup35 mutations (V269G, H348L, H348Q, K407E, D409W, and 
R419G) were obtained using site-specific mutagenesis. Only two of the six mutant proteins (eRF3-H348Q and eRF3-R419G) proved to be able to maintain the viability of yeast cells, although their presence resulted in a decrease in the growth rate. H348Q and R419G mutations, decreasing the rate of GTP hydrolysis, resulted in significant impairment of translation termination only on the UGAN stop codons (the stop codon translation level, being a significant one, increased by 3.7-16.8 times depending on the stop codon). At the same time, most of UAGN or UAAN codons maintained their termination codon properties in the presence of eRF3-H348Q or eRF3-R419G mutant proteins. The only exceptions were the tetranucleotides UAGC and UAAC, with the translation of the stop codon being 3.2-4.4 times higher than that of the wild-type eRF3 (Salas-Marco and Bedwell, 2004). Thus, the detection of eRF3 mutations that disrupt both GTPase activity and the recognition of specific stop signals provides evidence for eRF3 functions not to be limited to the simple recycling of eRF1. N406I or D409N substitutions in GTP-binding motif NKXD reduced affinity for GTP and eRF1-eRF3 association was markedly impaired (Kobayashi et al., 2004).

A potential phosphorylation site has been identified in the C-terminal Sup35 domain. It was found that the threonine residue at position 341 can be phosphorylated by protein kinase A in vitro. Provided this residue is replaced by asparagine (constitutive phosphorylation) or alanine (lack of phosphorylation), the translation termination accuracy is reduced by 4 and 2 times compared to wild protein type, respectively, with a disruption of the interaction of Sup35 and Sup 45 and a decrease in GTPase activity. It is noteworthy that unlike T341A, T341D reduced cell viability whereas, in the absence of the $\mathrm{N}$ domain, both mutant proteins were able to compensate for the disruption of the wild-type allele (Fabret et al., 2008). In subsequent work, it was shown that the T341D replacement causes synthetic lethality in combination with a prion $\left[\mathrm{PSI}^{+}\right]$, and the T341A mutation results in a weakening of $\left[\mathrm{PSI}^{+}\right]$. Thus, the authors showed the influence of the $\mathrm{C}$-domain on the $\left[\mathrm{PSI}^{+}\right]$properties and its role in the formation of fibrils (Kabani et al., 2011).

\subsubsection{Other mutations in the SUP35 gene}

The sup35-217 mutation results in the duplication of six amino acid residues (VNKMDL) (Table 1), forming one of the GTP-binding motifs $\left(\mathrm{N}_{406} \mathrm{~K}_{407} \mathrm{D}_{409}\right)$ (Kong et al., 2004). The mutation sup35-50 (T412P) is localized in the same region. It is possible that these mutations disrupt the GTPase activity of eRF3, resulting in suppression. Mutations in the GTP-binding motif (N153KMD156) of the yeast translation elongation factor eEF1A are known to cause suppression of all three stop codons (CarrSchmid et al., 1999).
In the case of sup35-222 mutation which is characterized by omnipotent nonsense suppression and reduced levels of Sup 35 and Sup 45 proteins, we could not detect any change in the coding region of SUP35 (Chabelskaya et al., 2004). Using whole-genome sequencing of the sup35-222 mutant strain one single-nucleotide variation was found 183 bp upstream of the SUP35 coding sequence (Table 1). It was suggested that this substitution destroys potential Abf1-binding site in the SUP35 promoter (Matveenko et al., 2019).

Sequence polymorphism of the SUP35 gene of the Peterhof genetic line (PGL) and the sequence presented in GenBank (S288C) was detected. All polymorphic sites were located in the non-conserved NM-domain and did not have their own phenotypic manifestation (Volkov et al., 2000).

\section{Termination factor eRF1}

\section{1. eRF1 STRUCTURE}

The structure and sequence of eRF1 are highly conservative (Frolova et al., 1994) although some organisms have several eRF1 paralogs that may vary in specificity of stop codon recognition (Liang et al., 2001; Chapman and Brown, 2004; Kim et al., 2005; Atkinson et al., 2008; Kim et al., 2008). The eRF1 protein consists of three domains: N, M, and C (Fig. 2, 3A).

The TASNIKS and YxCxxxF motifs, which are likely to play the role of specific "protein anticodons", are required for the $\mathrm{N}$-terminal domain to recognize a stop codon (Song et al., 2000; Frolova et al., 2002; Salas-Marco and Bedwell, 2004; 2006; Fan-Minogue et al., 2008; Cheng et al., 2009). The same domain is required for binding to the ribosome (Chavatte et al., 2001). The central M-domain with a conservative GGQ motif provides peptidyl-tRNA hydrolysis (Frolova et al., 1999; Seit-Nebi et al., 2001). The $\mathrm{C}$-terminal region of eRF1 containing the amino acid sequence GFGGIG (G/A) XLRY is responsible for the eRF1-eRF3 binding (Eurwilaichitr et al., 1999; Merkulova et al., 1999).

$\mathrm{X}$-ray analysis of human eRF1 and S.pombe (Song et al., 2000; Cheng et al., 2009) has shown the eRF1 molecule to resemble the tRNA molecule in three-dimensional structure, confirming the hypothesis of molecular mimicry proposed earlier for prokaryotic release factors (Ito et al., 1996).

\subsection{SUPPRESSOR MUTATIONS IN THE SUP45 GENE}

A specific feature of class- 1 release factors is their ability to recognize stop codons. Disruption of this function can also appear in the form of a suppressor effect, suggesting that the study of suppressor mutations can provide information on the mechanism of recognition of stop codons by class- 1 termination factors. The molecular mimicry 


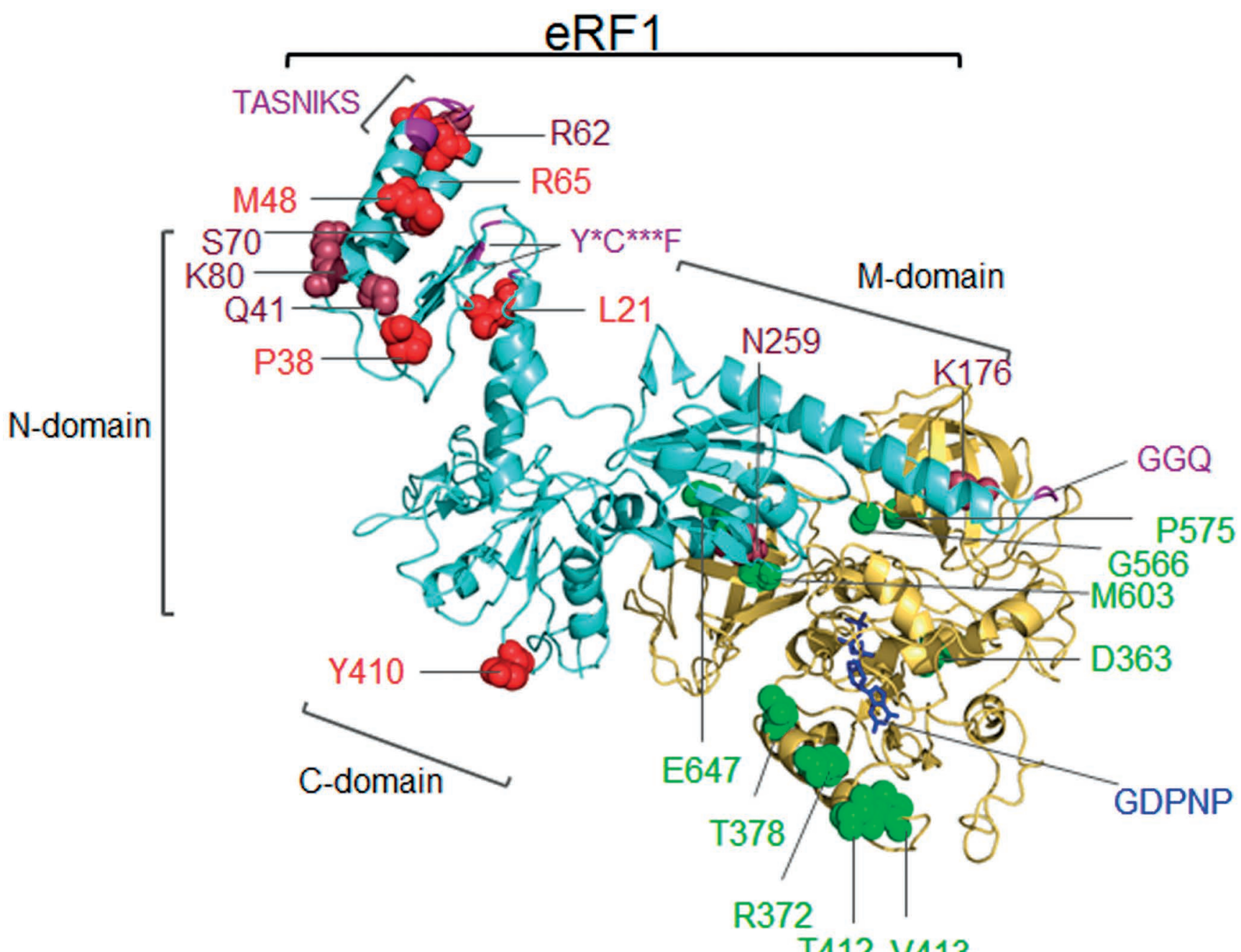

T412 V413

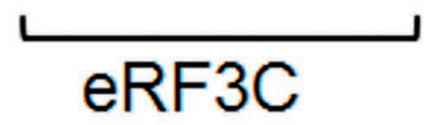

Fig. 2. Suppressor missense mutations in SUP45 and SUP35 genes studied in our laboratory.

All the mutations were denoted on 3D model of eRF1-eRF3C-GDPNP protein complex of S. cerevisiae (Preis et al., 2014). eRF1 (containing $\mathrm{N}, \mathrm{M}$ and C domains) and eRF3C (corresponding only C-terminal part of eRF3) are shown in aquamarine and yellow orange colors, respectively. Mutations in SUP45 gene that were also obtained in different works (see Table 4) are shown in red spheres ("hot spot"); while mutations obtained only once are shown in raspberry spheres. All single mutations sup35 obtained in our laboratory are shown in green spheres (see Table 1). The NIKS motif, the YxCxxxF motif and the GGQ motif of eRF1 are shown in purple ribbons. Nonhydrolyzable GTP analog guanylyl imidodiphosphate (GDPNP) is shown in blue sticks. The figure is generated by PyMOL (https://www.pymol.org/pymol).

hypothesis implies that class-1 release factors mimicking the structure of tRNA include "peptide anticodon" responsible for recognition of the stop codon and tRNA corresponding to the anticodon (Ito et al., 1996).

The selection of mutations in the SUP45 gene was performed by simultaneous reversion of nonsense TAA mutations located in two different genes (HIS7 and LYS9) (Moskalenko et al., 2003). To select the mutations, two different strains were used. The selection system specificity was associated with the search for such mutations in the SUP45 gene that would disrupt the interaction of eRF1 with only one of the three stop codons (in this case, the UAA). Sequencing the resulting mutations would allow identification of the eRF1 region responsible for recognizing nonsense codons.

\subsubsection{Nonsense mutations in the SUP45 gene}

We have characterized six sup45 nonsense mutations, with two of them located in the region of the SUP45 gene encoding the NM-domains of eRF1 (Table 4, Fig. 3B). Three sup45- $n$ mutations are located in the last third of the SUP45 gene, encoding the C-terminal domain of eRF1. Figure $3 \mathrm{~B}$ shows that most of the nonsense 
A

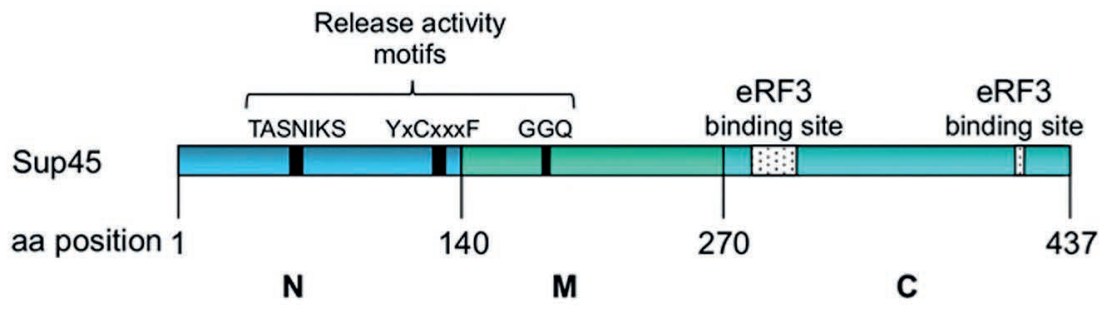

B

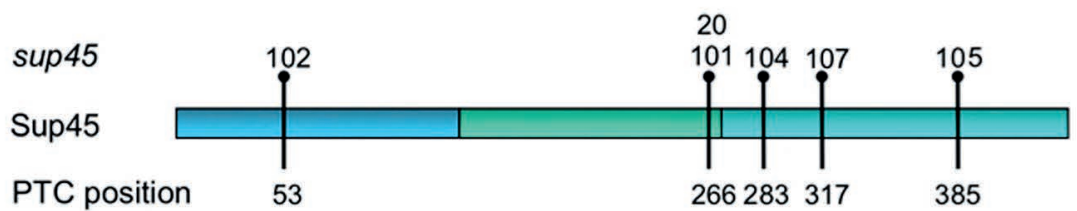

C

Y_eRF 1 ---MDNEVEKNIEIWKVKKLVQSLEKARGNGTSMISLVIPPKGQIPLYQKMLTDEYCTASNIKSRVNRLSVLSAITSTQQKLKLYNTLPKNGLVLYCGDI 100 h_eRF1 MADDPSAADRNVEIWKI KKLI KSLEAARGNGTSMISLI IPPKDQISRVAKMLADEFGTASNIKSRVNRLSVLGAITSVQQRLKLYNKVPPNGLVVYCGTI

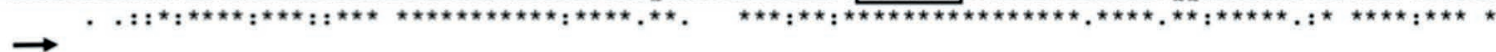
$\mathbf{N}$ Y_eRF1 ITEDGKEKKVTFDIEPYKPINTSL YLCDNKFATTEVLSELLQADDKFGFIVMDGQGTLFGSVSGNTRTVLHKFTVDLPKKHGR GGQSALRFARLREEKRHN 200 h_eRF 1 VTEEGKEKKVNIDFEPFKPINTSL YLCDNKP HTEALTALLSDDSKFGFIVIDGSGALFGTLQGNTREVLHKFTVDLPKKHGR GGO SALRFARLRMEKRHN

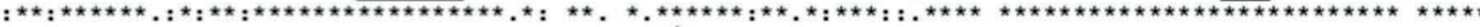
$\vec{M}$

$\Delta \boldsymbol{\Delta}$ $\Delta \mathbf{A}$

Y_eRF 1 YVRKVAEVAVQNFI TNDKVNVKGLILAGSADFKTDLAKSELFDPRLACKVISIVDVSYGGENGFNQAIELSAEALANVKYVQEKKLLEAYFDEISQDTGK 300 h_eRF 1 YVRKVAETAVQNFI TNDKVNVKGLILAGSADFKTDLAKSELFDPRLACKVISIVDVSYGGENGFNQAIELSAEALANVKY IQEKKLIGRYFDEISQDTGK

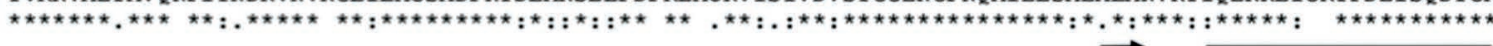
C eRF3

Y_eRF1 FCYGIDDTLKALDLGAVEKLIVFENLETIRYTF--KDAEDNEVIKFAEPEAKDKSFAIDKATGQEMDVVSEEPLIEWLAANYKNFGATLEFITDKSSEGA 400

h_eRF 1 YCFGVEDTLKALEMGAVEILIVYENLDIMRYVLHCQGTEEEKILYLTPEQEKDKSHFTDKETGQEHELIESMPLLEWFANNYKKFGATLEIVTDKSQEGS

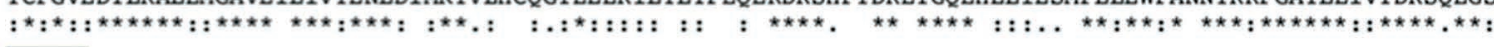

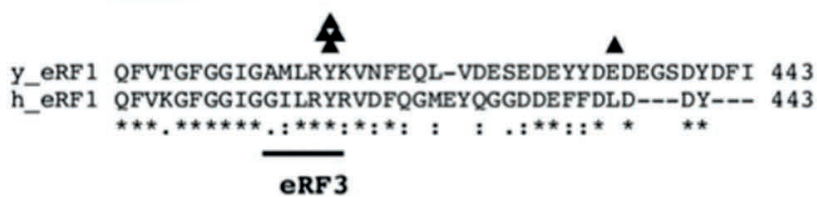

Fig. 3. The mutations obtained in the SUP45 gene.

A. Sup45p consists of three domains: N, M and C (Kisselev et al., 2003). N-domain includes two conservative release activity motives: TASNIKS and YXCXXF, which are required for stop codon recognition. M-domain contains conservative GGQ-motif performing peptidyl-tRNA hydrolysis. C-domain contains two eRF3 binding sites, the last one stimulates GTPase activity of eRF3 (Eurwilaichitr et al., 1999; Merkulova et al., 1999). B. Nonsense mutations in SUP45 gene obtained in our laboratory (Moskalenko et al., 2003). Numbers above Sup45 protein scheme correspond to numbers of the sup45 mutations. PTC (premature termination codon) positions match to the aa length of truncated proteins formed in the case of translation termination on the sup45 mutations. C. Suppressor missense mutations in SUP45 gene obtained in different laboratories (Breining and Piepersberg, 1986; Mironova et al. 1995; Stansfield et al. 1996; Bertram et al. 2000; Bradley et al 2003; Moskalenko et al., 2004; Valouev et al. 2004). Alignment of S. cerevisiae and H. sapiens eRF1s is shown. The triangle signs correspond single missense mutations (stacks of them correspond to hotspot mutation sites). Arrows below $\mathrm{N}$, $\mathrm{M}$ or $\mathrm{C}$ mean the start of corresponding domain of Sup45. TASNIKS, YxCXXF and GGQ-motives are framed; eRF3 binding sites are underlined.

sup45 mutations, isolated by various authors, are located precisely in the last third of the SUP45 gene.

\subsubsection{Missense mutations in SUP45 gene}

All the sup45 missense mutations, isolated on strain 1BD1606, are localized in the N-terminal eRF1 domain (Fig. 3C), confirming numerous data on the role of this domain in stop codon recognition. Five out of eleven isolated sup45- $m$ missense mutations result in methionine being substituted by isoleucine in the 48 position. That this region of the eRF1 protein is a "hot spot" confirms the fact that similar mutations were obtained by other authors by using different approaches for isolating mutations in the SUP45 gene. It should be noted that in our work, the unipotent phenotype with growth on 
Table 4. Mutations in the SUP45 gene, described in different works.

$\mathrm{X}$ means substitution of amino acid to stop codon; $\dagger$ indicate lethality of the mutation; * only single mutations are listed

\begin{tabular}{|c|c|c|c|c|}
\hline Method of selection & $\begin{array}{l}\text { Type of } \\
\text { mutation }\end{array}$ & Nucleotide changes & Amino acid changes & Reference \\
\hline $\begin{array}{l}\text { Suppression of ade1-14 (UGA) } \\
\text { and sensitivity to paromomycin } \\
\text { (strain 7B-D244) }\end{array}$ & Missense & T101C & L34S & $\begin{array}{l}\text { Breining and } \\
\text { Piepersberg, } \\
1986\end{array}$ \\
\hline $\begin{array}{l}\text { Suppression of ade1-14(UGA) and } \\
\text { his7-1(UAA) (strain P3990) }\end{array}$ & Missense & C193T & R65C & $\begin{array}{l}\text { Mironova et al., } \\
1995\end{array}$ \\
\hline $\begin{array}{l}\text { EMS mutagenesis (strain } \\
\text { BSC483/la) }\end{array}$ & Nonsense & C136T; C175T; C1078T; A1231T & Q46X; Q359X; Q360X; K411X & $\begin{array}{l}\text { Stansfield et al., } \\
1996\end{array}$ \\
\hline $\begin{array}{l}\text { Allosuppressor of SUQ5 (strain } \\
\text { MT552) }\end{array}$ & Missense & T665G & I222S & $\begin{array}{l}\text { Stansfield et al., } \\
\text { 1995b }\end{array}$ \\
\hline \multirow[t]{2}{*}{$\begin{array}{l}\text { Suppression of ade1-14 (UGA) } \\
\text { (strain IS31D7b/1c) or ade2- } \\
\text { 1(UAA) (strain TGB7a/5b) }\end{array}$} & Missense & $\begin{array}{l}\text { A94T; C113T; G144A; T203C; A219T; A320G; } \\
\text { N367G; A386G; G1282C }\end{array}$ & $\begin{array}{l}\text { I32F; P38L; M48I; V68I; V68A; } \\
\text { S74F; D110G; L123V; H129R; } \\
\text { E428Q }\end{array}$ & \multirow[t]{2}{*}{$\begin{array}{l}\text { Bertram et al., } \\
2000\end{array}$} \\
\hline & Nonsense & C1243T & Q415X & \\
\hline \multirow[t]{2}{*}{$\begin{array}{l}\text { Suppression of ade1-14 (UGA) } \\
\text { (strain 74-D694) }\end{array}$} & Missense & $\begin{array}{l}\text { G144T; G187T; T188A; G659A; G757T; } \\
\text { T824A; A1229C }\end{array}$ & $\begin{array}{l}\text { M48I; V63F; V63D; G220D; } \\
\text { V253F; V275D; Y410S }\end{array}$ & \multirow[t]{2}{*}{$\begin{array}{l}\text { Bradley et al., } \\
2003\end{array}$} \\
\hline & Nonsense & G366A; G1115A; G1243T & E366X; W372X; E414X & \\
\hline \multirow[t]{2}{*}{$\begin{array}{l}\text { Suppression of lys9-A21(UAA) and } \\
\text { his7-1(UAA) (strain 33G-D373) }\end{array}$} & Nonsense & G796T & E266X & $\begin{array}{l}\text { Our unpublished } \\
\text { data }\end{array}$ \\
\hline & Missense & $\begin{array}{l}\text { G528T; C777A (two times); A1229G (three } \\
\text { times) }\end{array}$ & $\begin{array}{l}\text { K176N; N259K (two times); } \\
\text { Y410C (three times) }\end{array}$ & \multirow[t]{3}{*}{$\begin{array}{l}\text { Moskalenko et } \\
\text { al., } 2004\end{array}$} \\
\hline $\begin{array}{l}\text { Suppression of ade1-14 (UGA) } \\
\text { and his7-1(UAA) (strain 2V-P3982) }\end{array}$ & Missense & $\begin{array}{l}\text { T62C (two times); C113T; A122C (two } \\
\text { times); G144T; G240C }\end{array}$ & $\begin{array}{l}\text { L21S (two times); P38L; Q41P } \\
\text { (two times); M48I; K80N }\end{array}$ & \\
\hline \multirow[t]{2}{*}{$\begin{array}{l}\text { Suppression of lys9-A21(UAA) and } \\
\text { his7-1(UAA) (strain 1B-D1606) }\end{array}$} & Missense & $\begin{array}{l}\text { T62C; G144T (five times); G185C (two } \\
\text { times); C209T }\end{array}$ & $\begin{array}{l}\text { L21S; M48I (five times); R62T } \\
\text { (two times); S70F }\end{array}$ & \\
\hline & Nonsense & T159A; G796T; T848A; T950G; G1153T & $\begin{array}{l}\text { Y53X; E266X; L283X; L317X; } \\
\text { E385X }\end{array}$ & $\begin{array}{l}\text { Moskalenko et } \\
\text { al., } 2003\end{array}$ \\
\hline $\begin{array}{l}\text { Spontaneous mutagenesis } \\
\text { (strain 33G-D373) }\end{array}$ & Missense & T67C; G228C/C229T & S30P; Q76H/Q77X & $\begin{array}{l}\text { Valouev et al., } \\
2004\end{array}$ \\
\hline $\begin{array}{l}\text { Spontaneous cryptic mutations } \\
\text { (strains 4V-P4482 and 10-2V- } \\
\text { P3982) }\end{array}$ & Missense & $\begin{array}{l}\text { G1199T } \\
\text { C224T }\end{array}$ & $\begin{array}{l}\text { G400V } \\
\text { T75I }\end{array}$ & $\begin{array}{l}\text { Aksenova et al., } \\
2006\end{array}$ \\
\hline Site directed mutagenesis & Missense & $\begin{array}{l}\text { T1261G; T1294G; T1261G/T1294G; } \\
\text { TC1261GA; TC1294GA; TC1261GA/TC1294GA }\end{array}$ & $\begin{array}{l}\text { S421A; S432A; S421A/S432A; } \\
\text { S421D; S432D; S421D/S432D }\end{array}$ & $\begin{array}{l}\text { Kallmeyer et al., } \\
2006\end{array}$ \\
\hline Site directed mutagenesis & Nonsense & C951T & L317X & $\begin{array}{l}\text { Zhouravleva et } \\
\text { al., } 2007\end{array}$ \\
\hline Site directed mutagenesis & Missense & T544G; T544G/G(A)546C(T) & Q182E; Q182N & $\begin{array}{l}\text { Studte et al., } \\
2008\end{array}$ \\
\hline Site directed mutagenesis & Missense & A1229C & Y410S & $\begin{array}{l}\text { Akhmaloka et } \\
\text { al., } 2008\end{array}$ \\
\hline \multirow[t]{2}{*}{ Site directed mutagenesis } & Nonsense & C228T; C726T & Q76X, R242X & \multirow{2}{*}{$\begin{array}{l}\text { Kiktev et al., } \\
2009\end{array}$} \\
\hline & Missense & TA157GG; A1154G; A1155T & Y53Q; E385Q; E385Y & \\
\hline PCR mutagenesis & Missense & $\begin{array}{l}\text { A79T; G151A; T174A; C226A; A227G; } \\
\text { A257G; G310A; T325C; A641G; A1079T; } \\
\text { A1079G }\end{array}$ & $\begin{array}{l}\text { N27Y; D51N; N58K; Q76K; } \\
\text { Q76R; K87E; E104K; F109L; } \\
\text { D214G; E360V; E360G }\end{array}$ & $\begin{array}{l}\text { *Hatin et al., } \\
2009\end{array}$ \\
\hline PCR mutagenesis & Missense & $\begin{array}{l}\text { CT148GC; A158N; G163At; A165G; } \\
\text { AA174GT; AA180GTt; AG183GT; AG186GT; } \\
\text { T322A; N523F; AA525GTt; AA528GTt; } \\
\text { G541Tt; G544Tt; A886G; A915G; A1071G; } \\
\text { A1164G; T1204A; A1231T }\end{array}$ & $\begin{array}{l}\text { L49A; E52A; G54Dt; T55A; } \\
\text { N58A; K60A t; S61A; R62A; } \\
\text { V107D; P174Q; K175A t; } \\
\text { K176A t; G180A t; G181A t; } \\
\text { T295A; T305A; T357A; T388A; } \\
\text { F401Y; Y410F }\end{array}$ & $\begin{array}{l}\text { Merritt et al., } \\
2010\end{array}$ \\
\hline
\end{tabular}


selective media characterized both the sup45-113 mutation (M48I) and the sup45-115 mutation (S70F). Mutation M48I also was described as unipotent by Bertram et al. (2000). At the same time, this mutation is reported as omnipotent on a different genotypic background (Moskalenko et al., 2004).

We compared the distribution of the amino acid substitutions in the eRF1 protein described in the literature that were caused by missense mutations. As can be seen from Figure 3C and Table 4, the N-domain positions, in which missense mutations in the SUP45 gene are found with different selection methods, are the same for many authors.

We have found two mutations (S70F and R62T) in $\mathrm{N}$-domain of Sup45 that has not been described previously in the literature. A substitution identified by sequencing the first mutant SUP45 allele (L34S) (Breining and Piepersberg, 1986) was in the same region. Also, one more mutant (sup45-3 containing R65C) was described in our laboratory earlier (Mironova et al., 1995). It makes it possible to conclude that there are only a few positions in the eRF1 protein where substitutions are not lethal and lead to nonsense suppression.

The remaining six mutations selected in our work on strain 33G-D373 result in amino acid substitutions in three sites, with one being in the central part of the yeast eRF1 (position 176), and two at the C-end of the molecule (position 259 and 410). Position 176 is close to one of the putative eRF1 interaction sites with eRF3 in S. pombe (amino acid residues 187-247 (Ito et al., 1998). According to our data, a mutation in this position disrupts the interaction of eRF1 and eRF3 in the two-hybrid system, possibly leading to the effect of nonsense suppression. Since the C-terminal amino acid residues of eRF1 are actively involved in the interaction with eRF3, the effect of mutations at positions 259 and 410 may also be associated with a disruption of this interaction. It was shown that substitution Y410S decreased binding affinity of eRF1 to eRF3 up to $20 \%$ of the wild type (Akhmaloka et al., 2008)

Thus, the distribution pattern of the mutations studied allows one to conclude that most of the missense mutations in the SUP45 gene, selected by the nonsense suppression effect, result in amino acid substitutions in the N-terminal part of the eRF1 molecule, limited by 21-80 positions. Mutations selected by the suppression effect of a nonsense mutation of the same type (TAA) can result in aa substitutions in different parts of the molecule, or they represent nonsense mutations in the SUP45 gene (Moskalenko et al., 2003). However, even in this variant of selection, most missense mutations affect the same positions in the eRF1 protein as mutations selected by the "classical" method. It is also significant that none of the missense mutations studied reduced the amount of eRF1 protein.
It is interesting to compare our data with the data obtained in the Stansfield laboratory (Bertram et al., 2000), where the mutants for the SUP45 gene were selected by using a library of mutagenized plasmids carrying the SUP45 gene. The goal of this work was to identify the mutant SUP45 alleles exhibiting a "unipotent" suppressor effect that suppresses only one type of nonsense mutations. However, although the mutations obtained had different codon specificity at the phenotypic level, it was found that in their presence, all three stop codons were actually read, albeit with different efficiencies (Bertram et al., 2000). Most of the mutations obtained in this work also affect the $\mathrm{N}$-terminal part of the protein (positions $32,38,48,68,74)$. At the same time, some of them affected the same positions in the protein as the mutations studied by us (positions 38 and 48). In addition, three amino acid substitutions were located somewhat to the right of the site marked in our work (positions $110,123,129)$, with one more substitution located at the C-end of the molecule (position 428).

This work focused mainly on mutations affecting the $\mathrm{N}$-terminal part of the molecule. In addition to our data suggesting that the mutations in question did not affect the interaction with the eRF3 protein, it was shown that these mutants were not influenced by the binding to the ribosome. Thus, the most likely function impaired by amino acid substitutions in the $\mathrm{N}$-terminal part of the eRF1 protein is the interaction of eRF1 with stop codons.

The involvement of the N-terminal domain in recognition of a stop codon was shown in vivo (Bertram et al., 2000) since mutations in this region resulted in a change in the specificity of stop codon recognition by the eRF1 protein. Genetic screening of mutants characterized by a unipotent suppressor phenotype (that is, leading to the suppression of only one stop codon) revealed a series of missense mutations (Bertram et al., 2000) (Fig. 3C, Table 4). Most of them were located in the gap between the two $\alpha$-helices and the opposite $\beta$-layer of the $\mathrm{N}$-domain eRF1. It is hypothesized that it is these structures that form the surface of eRF1 involved in the interaction with mRNA. With all isolated mutants revealing a weak omnipotent suppressor phenotype, a hypothesis was put forward that stop codon decoding in eukaryotes is an integral process-that is, the recognition of a single nonsense codon cannot be completely separated from the recognition of other termination codons. This hypothesis suggests that stop codon decoding in eukaryotes is more complex and therefore different from sense codon decoding using tRNA (Bertram et al., 2000).

Additional data concerning the molecular mechanisms involved in the discrimination of stop codons were obtained in experiments using proteins of the eRF1 family from organisms using the UAG codon or the UAA 
and UAG codons as sense codons (see the review by Lozupone et al., 2001). It is evident that eRF1 should no longer recognize UAG (or UAA and UAG) in these organisms as translation termination signals. In this regard, it was suggested that amino acid residues that determine the specificity of eRF1 to a specific stop codon could be identified by comparing the eRF1sequences in organisms with non-standard genetic code with organisms that have a universal genetic code (Karamyshev et al., 1999). The comparison of sequences did allow a number of hypotheses explaining the decoding process to be formulated (Inagaki and Doolittle, 2001; Lozupone et al., 2001; Muramatsu et al., 2001; Inagaki et al., 2002). Unfortunately, these models were not confirmed by experiment, with most of the experiments making it possible to establish that the recognition of a stop codon is not a linear sequence of amino acid residues eRF1, but more complex structural motif (s) (Ito et al., 2002; SeitNebi et al., 2002; Chavatte et al., 2003; Salas-Marco et al., 2006).

A large collection of point mutations in yeast SUP45 was obtained and characterized (Hatin et al., 2009). Among them were mutations that significantly increased translation termination efficiency, some of which are listed in Table 4. However, most of the mutants contained two or three aa changes (Hatin et al., 2009). From twenty new sup 45 mutants six were inviable (Table 4) (Merritt et al., 2010). A large number of interesting conclusions came from this work, including strain-specific differences in the stop codon readthough, and between in vivo and in vitro experiments. Extensive characterization of sup 45 mutants from different collections as well as new ones allowed authors to show that various phenotypes associated with these mutants are independent of defects in translation termination (Merritt et al., 2010).

Using site-directed mutagenesis, Sup 45 phosphorylation sites were identified (Kallmeyer et al., 2006), and the effect of Sup45 methylation on translation termination accuracy was shown (Studte et al., 2008).

\section{Appearance of nonsense mutations in SUP45 and SUP35 genes}

In our work, nonsense mutations in the essential SUP45 and SUP35 genes were shown for the first time not to cause lethality in the absence of suppressor tRNA.Currently, several processes are known that can overcome the negative effect associated with the presence of nonsense codons. In particular, the presence of mutant (and in some cases non-mutant) tRNA in the cell results in the suppression of stop codons (see the review by Beier and Grimm, 2001). The so-called "weak" termination context and/or the RNA secondary structure specificity can also result in stop codon translation (see review Bertram et al., 2001). In our work it was shown that viability of sup 45 nonsense mutants is supported by diverse mechanisms that control the final amount of functional Sup45 in cells (Kiktev et al., 2009).

Many laboratory strains, as well as natural populations of E. coli, contain suppressor tRNA ${ }^{\mathrm{UAG}}$ (Tate et al., 1996). The mutation rate in at least some tRNA genes is known to be significantly increased (Ito-Harashima et al., 2002). It is highly unlikely that the initial strains 33G-D373 and 1B-D1606 used in our work contain mutant suppressor tRNA. Firstly, such suppressors are usually codon-specific, and their presence would result in the appearance of nonsense sup 45 or sup 35 mutations of only one type (for example, TAA). In our work, mutations of different types were isolated: (TAA) and (TGA), in the case of sup45- $n$, and (TAA) and (TAG) for sup35$n$. Secondly, all the sup45- $n$ and sup35- $n$ mutations described in our work are recessive, while mutations in the tRNA genes are usually dominant. All sup $35-n$ transformants selected during plasmid shuffle experiments and containing nonsense sup35 mutations on the plasmid retained their recessive suppressor phenotype, while in the case of additional mutations this effect should be dominant. Moreover, it is known that suppressor mutations in tRNA genes are generally incompatible with sup35 and sup 45 mutations (Song and Liebman, 1985). Thirdly, the parent strains, as well as the strains used to assess the viability of the sup45- $n$ and sup35- $n$ mutations, did not possess the tested in vitro suppressor activity. In strains 1A-D1628 and 16A-D1608 used in plasmid substitution experiments, no suppression of ade1-14 (TGA), his71 (TAA), trp1-289 (TAG) and lys9-A21 (TAA) mutations was found. In addition, the sequenced genome of strain S288C, the isogenic derivatives of which were used in plasmid substitution experiments, does not contain mutations in the tRNA genes (Percudani et al., 1997, Drozdova et al., 2016).

Non-lethal nonsense mutations in the SUP35 and SUP45 genes were described by other authors (Zhou et al., 1999; Bradley et al., 2003), but in those cases, it remained unknown whether the parent strain possessed any suppressor activity. The nonsense mutations in the SUP45 (sup45-0) gene were also isolated in the presence of the SUQ5 mutation, resulting in the appearance of a suppressor tRNA ${ }^{\text {Ser }}$ in the cell; but these mutations were lethal in the absence of the SUQ5 mutation (Stansfield et al., 1996). We have estimated the content of "potential" stop codons (codons, single mutations in which can lead to the appearance of stop codons) in the SUP45 gene (Table 2). In the case of codons, single mutations in which can lead to the appearance of two different stop codons (for example, replacing a TTA codon in the second position will result in a TAA codon or TGA), the corresponding frequencies were equally divided between the two classes. The data given in Table 2 indicate that po- 
tential stop codons are fairly evenly distributed across the SUP45 gene sequence. In the regions encoding the N, M and C-domains, such codons account for $39.1 \%, 30.8 \%$ and $38.3 \%$ of the total number of codons, respectively.

Thus, the uneven distribution of nonsense mutations in the SUP45 gene cannot be accounted for by the increased codon content, a single substitution in which can result in the appearance of a stop codon. It is possible that the preferred localization of nonsense mutations in the region encoding the $\mathrm{C}$-domain is related to the nucleotide context features. The absence of mutations resulting in the appearance of the stop codon UAG among the sup45- $n$ mutations can be explained by the specificity of selection carried out by the simultaneous reversion of two other mutations. At the same time, in the screening of Ade ${ }^{+}$revertants (a strain containing the ade1-14 mutation (TGA) was used), two sup45- $n$ TAG mutations and one TAA were isolated (Bradley et al., 2003). The fact that only one of the five sup45-n mutations isolated (Moskalenko et al., 2003) caused the appearance of the TGA codon can be explained by the reduced content of potential UGA codons in the SUP45 gene sequence. Indeed, the SUP45 gene sequence contains $14 \%$ of such codons as compared with $33 \%$ and $53 \%$ for potential codons UAG and UAA, respectively (the number of potential stop codons is taken as $100 \%$ ) (Table 2).

The termination efficiency is known to depend on the local context surrounding the stop codon (see reviews by Tate and Mannering, 1996; Kisselev and Buckingham, 2000; Bertram et al., 2001). Although the local context in yeast and bacteria is different, there is a fairly strong correlation between the frequency of a particular nucleotide being present at position +4 in the natural termination sites and the termination efficiency at the corresponding tetranucleotide stop codon (Bonetti et al., 1995; Poole et al., 1995). According to these data, the relative level of the full-length eRF1 protein correlated with the strength of the translation termination signal: in the case of the strongest (UAAG) and weakest (UAAC) termination signals, the number of eRF1 was $8 \%$ and $32 \%$ of the wild-type level, respectively (Moskalenko et al., 2003).

In the case of the UGA codon, the translation termination efficiency decreases in the order $\mathrm{G}>\mathrm{U}>\mathrm{A}>\mathrm{C}$ depending on the position $(+4)$ while for the UAG codon, this order is different $(A>U>C>G)$ (Bonetti et al., 1995). Indeed, the sup45-107 mutation (TGAA) is located in a weak terminating context. At the same time, the replacement of the TGA codon by TAG in the mutant sup45-107 allele led to a change in the local context (TGAA $\rightarrow$ TAGA) and lethality (Moskalenko, 2003). Thus, the sup45- $n$ mutations can be supposed to be located in a "weak" terminating context.

It should be noted that all sup45-0 mutations that caused the UAA codon to appear in the presence of
SUQ5 (Stansfield et al., 1996) were located in a "strong" context since purine was in the +4 position of these mutations. However, since one of our viable sup45- $n$ mutants (sup45-13) contained an allele identical to sup4518 (Stansfield et al., 1996), the inviability of the sup450 mutants in the absence of SUQ5 cannot be explained by the influence of the context. A mathematical model predicting the Sup45 translational readthrough negative feedback loop control was created; this model anticipates that manifestation of sup45-n mutations will depend on nucleotide context, as well as on the level of tRNA suppression and amount of SUP45 mRNA (Betney et al., 2012).

We have not found an apparent correlation between the location of the nonsense mutation in the SUP35 gene coding sequence and the amount of the full-length eRF3 protein. It is known that not only the nucleotide at position +4 , but also the other nucleotides surrounding the stop codon, affect the efficiency of translation termination (Mottagui-Tabar et al., 1998; Cassan and Rousset, 2001; Namy et al., 2001; 2002; Liu, 2005). It is assumed that this effect is due to the interaction of these mRNA sites with various components of the translation apparatus (see review by Tate et al., 1996; Bertram et al., 2001). We have compared the nucleotide environment of stop codons for the nonsense sup 45 and sup 35 mutations that were isolated in our works (Table 3).

Analysis of the nucleotide context revealed that among 16 sup 45- $n$ and sup35- $n$ mutations, 8 contain adenine at position -1, 12 contain adenine at position -2, and 8 contain adenine in both positions. The presence of two adenines immediately before the stop codon was shown to facilitate translation of the stop codon in yeast cells (Tork et al., 2004). Some of the mutations are surrounded by codons CAA, which are known to increase the level of suppression (Kopczynski et al., 1992; Bonetti et al., 1995). It is possible for all the sup45- $n$ and sup35- $n$ mutations to be located in a weak terminating context.

\section{Suppression due to prion $\left[P S I^{+}\right]$}

Sup35 protein aggregation in a yeast cell leads to the appearance of a prion $\left[\mathrm{PSI}^{+}\right]$. In order to be considered a prion, a genetic determinant must satisfy a number of genetic criteria (Wickner et al., 1995). One of them is the similarity of phenotypes in mutants by the structural gene of the prion and prion-associated phenotypes. The main phenotypic manifestation of the $\left[\mathrm{PSI}^{+}\right]$factor is a decreased translation accuracy (see review Cox et al., 1988), which is similar to the mutation effect in the SUP35 gene, the structural gene of $\left[\mathrm{PSI}^{+}\right]$. Different strains of $\left[\mathrm{PSI}^{+}\right]$exhibit different suppression efficiencies (Derkatch et al., 1996) which can vary from 0.2 to $35 \%$ (Bidou et al., 2000; True et al., 2000; Uptain et al., 2001; Kiktev et al., 2009). Early works argued that the $\left[P^{+} I^{+}\right]$ 
factor does not affect the growth rate of yeast strains (see the review by Cox et al., 1988). Studies conducted on seven yeast strains using 150 different culture conditions showed that in $50 \%$ of cases $\left[\mathrm{PSI}^{+}\right]$did not really affect growth, while the other cases demonstrated both growth inhibition and stimulation in the presence of $\left[\mathrm{PSI}^{+}\right]$(True et al., 2000). In some cases, the $\left[\mathrm{PSI}^{+}\right]$ factor led to a change in the colony morphology (True et al., 2000) and cell sensitivity to paromomycin at $20^{\circ} \mathrm{C}$ (Cosson et al., 2002). A systematic comparison of the phenotype of $\left[\mathrm{PSI}^{+}\right]$strains with isogenic $\left[\mathrm{psi}^{-}\right]$strains, as well as isogenic strains carrying the sup35 (C653R) mutation, in $70 \%$ of cases, revealed a coincidence of $\left[\mathrm{PSI}^{+}\right]$-induced phenotypes with phenotypes caused by the SUP35 mutation. At the same time, in $30 \%$ of cases, such a correlation was not observed (True et al., 2004). This fact allowed the authors to suggest that the presence of $\left[\mathrm{PSI}^{+}\right]$factor in yeast cells can provide them with selective advantages due to the expression of pseudogenes or 3' untranslated RNA under normal conditions (see the review by Shorter and Lindquist, 2005). Despite the fact that this hypothesis remains to be proved and provokes active criticism from a number of researchers (see, for example, Nakayashiki et al., 2005), it is obvious that in some cases the phenotype caused by the presence of the factor $\left[\mathrm{PSI}^{+}\right]$may differ from the phenotype caused by the SUP35 mutations. A possible explanation for such differences may be that in the cited work (True et al., 2004), the phenotypes caused by the presence of $\left[\mathrm{PSI}^{+}\right]$ were compared with phenotypes of only one sup $35 \mathrm{mu}-$ tation. Various sup 35 mutations are known to reveal various manifestations, including thermosensitivity or its absence, different suppression efficacy, sensitivity or resistance to benomyl, paromomycin, etc. The reasons for these differences are not currently known. At the same time, the $\left[\mathrm{PSI}^{+}\right]$factor, originally described as the allosuppressor SUQ5 (Cox et al., 1988), does not on its own suppress all nonsense mutations. Hence, early studies reported $\left[\mathrm{PSI}^{+}\right]$not to suppress TAG mutations and most TAA mutations (Liebman and Sherman, 1979). It should be noted that the quantitative assessment of the suppression effectiveness that showed $\left[\mathrm{PSI}^{+}\right]$to suppress all three stop codons was carried out on a strain containing the SUQ5 mutation (Firoozan et al., 1991). The mutant tRNA ${ }^{\text {Ser }}$ resulting from the SUQ5 mutation is known not only to suppress the UAA codon but, in the presence of the sal4-2 mutation, to have an allosuppressive effect on the UAG codon (Stansfield et al., 1995b). The [PSI $\left.{ }^{+}\right]$factor has been reported to suppress mutations in $c y c 1-72$, trp5-48, cyc1-179 (TAA) (Liebman and Sherman, 1979), met8-1, lys2-A12 (TAG) (Ono et al., 1986; Chernoff et al., 1995), lys2-101 (TGA) (Ono et al., 1986), lys2-87, ade1-14, thr4-B15 (TGA) (Chernoff et al., 1995), ade1-6, leu2-2, his7-1, lys9-A21, ade2-1 (TAA) (Derkatch et al., 1996). It is difficult to compare the data of various re- searchers on the specificity of $\left[\mathrm{PSI}^{+}\right]$-mediated suppression due to the differences in the strains used, as well as due to different variants of the $\left[\mathrm{PSI}^{+}\right]$factor.

\section{Concluding remarks}

While the main goal of this review was to summarize known data about suppressor mutations isolated in SUP35 or SUP45 genes, some other mutations in these genes were not discussed. A number of mutations named $P N M$ (from " $\left[P S I^{+}\right]$no more", Doel et al., 1994) have been identified in the SUP35 gene, affecting the maintenance of the $\left[\mathrm{PSI}^{+}\right]$factor. Such mutations are not known for the SUP45 gene. A significant amount of antisuppressor mutations was obtained in the SUP45 gene (Hatin et al., 2007), only some of them are shown in Table 4 . We also did not discuss the role of numerous proteins such as ABCE1, Dbp5, PABP, Hrp1, Pub1, Upfs and so on that also take part in translation termination (see Tieg and Krebber, 2013; Schuller and Green, 2018 for recent review).

Multiple effects of mutations in the SUP35 and SUP45 genes have been revealed, but their origin still needs to be clarified. It is possible that not only are the SUP35 and SUP45 genes involved in translation, but they also participate in the control of other cellular processes. However, an alternative explanation is not improbable: pleiotropic effects may result from a translation termination disruption in the sup 35 and sup 45 mutants. Thus, the story of sup35 and sup45 mutations is not finished.

\section{Acknowledgments}

We are very grateful to Stanislav Bondarev for his help with the program PyMOL.

\section{References}

Akhmaloka, P. E. S. and Subandi, F. M. 2008. Mutation at tyrosine in AMLRY (GILRY like) motif of yeast eRF1 on nonsense codons suppression and binding affinity to eRF3. International journal of biological sciences 4(2):87. https://doi.org/10.7150/ijbs.4.87

Aksenova, A. Y., Volkov, K. V., Rovinsky, N. S., Svitin, A. V., and Mironova, L. N. 2006. Phenotypic expression of epigenetic determinant $\left[\mathrm{ISP}^{+}\right]$in Saccharomyces cerevisiae depends on the combination of sup35 and sup45 mutations. Molecular Biology 40(5):758-763. https://doi. org/10.1134/S0026893306050104

Alkalaeva, E. Z., Pisarev, A. V., Frolova, L. Y., Kisselev, L. L., and Pestova, T. V. 2006. In vitro reconstitution of eukaryotic translation reveals cooperativity between release factors eRF1 and eRF3. Cell 125:1125-1136. https://doi. org/10.1016/j.cell.2006.04.035

All-Robyn, J. A., Kelley-Geraghty, D., Griffin, E., Brown, N., and Liebman, S. W. 1990. Isolation of omnipotent suppressors in an [eta+] yeast strain. Genetics 124:505-514.

Atkinson, G. C., Baldauf, S. L., and Hauryliuk, V. 2008. Evolution of nonstop, no-go and nonsense-mediated mRNA decay and their termination factor-derived components. BMC Evolutionary Biology 8 (1):290. https://doi. org/10.1186/1471-2148-8-290 
Beaudet, A. L. and Caskey, C.T. 1971. Mammalian peptide chain termination, II. Codon specificity and GTPase activity of release factor. Proceedings of the National Academy of Sciences USA 68:619-624. https://doi.org/10.1073/ pnas.68.3.619

Beier, H. and Grimm, M. 2001. Misreading of termination codons in eukaryotes by natural nonsense suppressor tRNAs. Nucleic Acids Research 29:4767-4782. https://doi. org/10.1093/nar/29.23.4767

Bertram, G., Bell, H. A., Ritchie, D. W., Fullerton, G., and Stansfield, I. 2000. Terminating eukaryote translation: domain 1 of release factor eRF1 functions in stop codon recognition. RNA 6:1236-1247. https://doi.org/10.1017/ S1355838200000777

Bertram, G., Innes, S., Minella, O., Richardson, J. P., and Stansfield, I. 2001. Endless possibilities: Translation termination and stop codon recognition. Microbiology 147:255269. https://doi.org/10.1099/00221287-147-2-255

Betney, R., de Silva, E., Mertens, C., Knox, Y., Krishnan, J., and Stansfield, I. 2012. Regulation of release factor expression using a translational negative feedback loop: a systems analysis. RNA 18:2320-2334. https://doi. org/10.1261/rna.035113.112

Bidou, L., Stahl, G., Hatin, I., Namy, O., Rousset, J.-P., and Farabaugh, P.J. 2000. Nonsense-mediated decay mutants do not affect programmed -1 frameshifting. RNA 6:952961. https://doi.org/10.1017/S1355838200000443

Bonetti, B., Fu, L., Moon, J., and Bedwell, D. M. 1995. The efficiency of translation termination is determined by a synergistic interplay between upstream and downstream sequences in Saccharomyces cerevisiae. Journal of Molecular Biololgy 251:334-345. https://doi.org/10.1006/ jmbi.1995.0438

Bradley, M. E., Bagriantsev, S., Vishveshwara, N., and Liebman, S. W. 2003. Guanidine reduces stop codon readthrough caused by missense mutations in SUP35 or SUP45. Yeast 20:625-632. https://doi.org/10.1002/yea.985

Breining, P., Surguchov, A. P., and Piepersberg, W. 1984. Cloning and identification of a DNA fragment coding for the sup1 gene of Saccharomyces cerevisiae. Current Genetics 8:467-470. https://doi.org/10.1007/BF00433913

Breining, P. and Piepersberg, W. 1986. Yeast omnipotent supressor SUP1 (SUP45): nucleotide sequence of the wild type and a mutant gene. Nucleic Acids Res 14:5187-5197. https://doi.org/10.1093/nar/14.13.5187

Carr-Schmid, A., Durko, N., Cavallius, J., Merrick, W. C., and Kinzy, T. G. 1999. Mutations in a GTP-binding motif of eukaryotic elongation factor $1 \mathrm{~A}$ reduce both translational fidelity and the requirement for nucleotide exchange. Journal of Molecular Biololgy 274:30297-30302. https:// doi.org/10.1074/jbc.274.42.30297

Cassan, M. and Rousset, J.-P. 2001. UAG readthrough in mammalian cells: effect of upstream and downstream stop codon contexts reveal different signals. BMC Molecular Biology 2:3. https://doi.org/10.1186/1471-2199-2-3

Chabelskaya, S., Kiktev, D., Inge-Vechtomov, S., Philippe, M., and Zhouravleva, G. 2004. Nonsense mutations in the essential gene SUP35 of Saccharomyces cerevisiae are non-lethal. Molecular Genetics and Genomics 272:297307. https://doi.org/10.1007/s00438-004-1053-1

Chapman, B. and Brown, C. 2004. Translation termination in Arabidopsis thaliana: characterisation of three versions of release factor 1. Gene 341:219-225. https://doi. org/10.1016/j.gene.2004.06.053

Chavatte, L., Frolova, L., Kisselev, L., and Favre, A. 2001. The polypeptide chain release factor eRF1 specifically contacts the $S^{4} U G A$ stop codon located in the $A$ site of eukaryotic ribosomes. European Journal of Biochem- istry 268:2896-2904. https://doi.org/10.1046/j.14321327.2001.02177.x

Chavatte, L., Kervestin, S., Favre, A., and Jean-Jean, O. 2003. Stop codon selection in eukaryotic translation termination: comparison of the discriminating potential between human and ciliate eRF1s. The EMBO Journal 22:1644-1653. https://doi.org/10.1093/emboj/cdg146

Cheng, Z., Saito, K., Pisarev, A. V., Wada, M., Pisareva, V.P., Pestova, T. V., Gajda, M., Round, A., Kong, C., Lim, M., Nakamura, Y., Svergun, D. I., Ito, K., and Song, H. 2009. Structural insights into eRF3 and stop codon recognition by eRF1. Genes \& Development 23:1106-1118. https://doi. org/10.1101/gad.1770109

Chernoff, Y. O., Derkatch, I. L., Dagkesamanskaya, A. R., Tikhomirova, V. L., and Ter-Avanesyan, M.D. 1988. Nonsense-suppression by amplification of translational protein factor gene. Doklady Akademii Nauk SSSR 301:12271229. (In Russian)

Chernoff, Y. O., Derkatch, I. L., and Inge-Vechtomov, S. G. 1993. Multicopy SUP35 gene induces de-novo appearance of psi-like factors in the yeast Saccharomyces cerevisiae. Current Genetics 24:268-270. https://doi.org/10.1007/ BF00351802

Chernoff, Y. O., Lindquist, S. L., Ono, B., Inge-Vechtomov, S. G., and Liebman, S. W. 1995. Role of the chaperone protein Hsp104 in propagation of the yeast prion-like factor [PS/ ${ }^{+}$. Science 268:880-884. https://doi.org/10.1126/science.7754373

Cosson, B., Couturier, A., Chabelskaya, S., Kiktev, D., IngeVechtomov, S., Philippe, M., and Zhouravleva, G. 2002. Poly (A)-binding protein acts in translation termination via eukaryotic release factor 3 interaction and does not influence $\left[\mathrm{PSI}^{+}\right]$propagation. Molecular and Cellular Biology 22:3301-3315. https://doi.org/10.1128/ MCB.22.10.3301-3315.2002

Cox, B. 1965. $\left[\mathrm{PSI}^{+}\right]$, a cytoplasmic suppressor of supersuppressor in yeast. Heredity 20:505-521. https://doi. org/10.1038/hdy.1965.65

Cox, B., Tuite, M. F., and McLaughlin, C.S. 1988. The $\psi$ factor of yeast: A problem in inheritance. Yeast 4:159-178. https://doi.org/10.1002/yea.320040302

Cox, B.S. 1971. A recessive lethal super-suppressor mutation in yeast and other $\psi$ phenomena. Heredity 26:211. https://doi.org/10.1038/hdy.1971.28

Craigen, W. J., Cook, R. G., Tate, W. P., and Caskey, C. T. 1985. Bacterial peptide chain release factors: conserved primary structure and possible frameshift regulation of release factor 2. Proceedings of the National Academy of Sciences USA 82:3616-3620. https://doi.org/10.1073/ pnas.82.11.3616

Craigen, W.J. and Caskey, C. T. 1987. The function, structure and regulation of E. coli peptide chain release factors. Biochimie 69:1031-1041. https://doi.org/10.1016/03009084(87)90003-4

Crouzet, M. and Tuite, M. F. 1987. Genetic control of translational fidelity in yeast: molecular cloning and analysis of the allosuppressor gene SAL3. Molecular Genetics and Genomics 210:581-583. https://doi.org/10.1007/ BF00327216

Crouzet, M., Izgu, F., Grant, C. M., and Tuite, M. F. 1988. The allosuppressor gene SAL4 encodes a protein important for maintaining translational fidelity in Saccharomyces cerevisiae. Current Genetics 14:537-543. https://doi. org/10.1007/BF00434078

Derkatch, I. L., Chernoff, Y. O., Kushnirov, V. V., Inge-Vechtomov, S. G., and Liebman, S. W. 1996. Genesis and variability of $\left[\mathrm{PSI}^{+}\right]$prion factors in Saccharomyces cerevisiae. Genetics 144:1375-1386. 
Didichenko, S. A., Ter-Avanesyan, M.D., and Smirnov, V. N. 1991. Ribosome-bound EF-1a-like protein of yeast Saccharomyces cerevisiae. European Journal of Biochemistry 198:705-711. https://doi.org/10.1111/j.1432-1033.1991. tb16070.x

Doel, S. M., McCready, S. J., Nierras, C. R., and Cox, B. 1994. The dominant PNM2- mutation which eliminates the $\psi$ factor of Saccharomyces cerevisiae is the result of a missense mutation in the SUP35 gene. Genetics 137:659-670.

Drozdova, P. B., Tarasov, O. V., Matveenko, A. G., Radchenko, E.A., Sopova, J.V., Polev, D. E., Inge-Vechtomov S. G., and Dobrynin, P.V. 2016. Genome sequencing and comparative analysis of Saccharomyces cerevisiae strains of the Peterhof genetic collection. PLoS One 11(5):e0154722. https://doi.org/10.1371/journal. pone. 0154722

Ebihara, K. and Nakamura, Y. 1999. C-terminal interaction of translational release factors eRF1 and eRF3 of fission yeast: G-domain uncoupled binding and the role of conserved amino acids. RNA 5(5):739-750. https://doi. org/10.1017/S135583829998216X

Ehrenberg, M. and Tenson, T. 2002. A new beginning of the end of translation. Nature Structural \& Molecular Biology 9:85. https://doi.org/10.1038/nsb0202-85

Eurwilaichitr, L., Graves, F. M., Stansfield, I., and Tuite, M. F. 1999. The C-terminus of eRF1 defines a functionally important domain for translation termination in Saccharomyces cerevisiae. Molecular Microbiology 32:485-496. https://doi.org/10.1046/j.1365-2958.1999.01346.x

Eustice, D. C., Wakem, L.P., Wilhelm, J. M., and Sherman, F. 1986. Altered $40 \mathrm{~S}$ ribosomal subunits in omnipotent suppressors of yeast. Journal of Molevular Biology 188:207214. https://doi.org/10.1016/0022-2836(86)90305-0

Fabret, C., Cosnier, B., Lekomtsev, S., Gillet, S., Hatin, I., Maréchal, P. Le, and Rousset, J.P. 2008. A novel mutant of the Sup35 protein of Saccharomyces cerevisiae defective in translation termination and in GTPase activity still supports cell viability. BMC Molecular Biology 9(1):22. https://doi.org/10.1186/1471-2199-9-22

Fan-Minogue, H., Du, M., Pisarev, A. V., Kallmeyer, A. K., SalasMarco, J., Keeling, K. M., Thompson, S. R., Pestova, T. V., David M., and Bedwell, D. M. 2008. Distinct eRF3 requirements suggest alternate eER1 conformations mediate peptide release during eukaryotic translation termination. Molecular Cell 30:599-609. https://doi. org/10.1016/j.molcel.2008.03.020

Firoozan, M., Grant, C. M., Duarte, J. A. B., and Tuite, M. F. 1991. Quantitation of readthrough of termination codons in yeast using a novel gene fusion assay. Yeast 7:173-183. https://doi.org/10.1002/yea.320070211

Franzmann, T. M., Jahnel, M., Pozniakovsky, A., Mahamid, J., Holehouse, A. S., Nüske, E., Richter, D., Baumeister, W., Grill, S. W., Pappu, R. V., Hyman A. A., and Alberti S. 2018. Phase separation of a yeast prion protein promotes cellular fitness. Science 359(6371):eaao5654. https://doi. org/10.1126/science.aao5654

Frolova, L.Y., Dalphin, M.E., Justesen, J., Powell, R. J., Drugeon, G., McCaughan, K. K., Kisselev, L. L., Tate, W. P., and Haenni, A. L. 1993. Mammalian polypeptide chain release factor and tryptophanyl-tRNA synthetase are distinct proteins. The EMBO Journal 12:4013-4019. https:// doi.org/10.1002/j.1460-2075.1993.tb06079.x

Frolova, L. Y., Goff, X. Le, Rasmussen, H. H., Cheperegin, S., Drugeon, G., Kress, M., Arman, I., Haenni, A.-L., Celis J. E., Phllippe M., Justesen J., and Kisselev L. 1994. A highly conserved eukaryotic protein family possessing properties of polypeptide chain release factor. Nature 372:701703. https://doi.org/10.1038/372701a0
Frolova, L.Y., Goff, X. Le, Zhouravleva, G., Davydova, E. Philippe, M., and Kisselev, L. L. 1996. Eukaryotic polypeptide chain release factor eRF3 is an eRF1- and ribosomedependent guanosine triphosphatase. RNA 2:334-341.

Frolova, L. Y., Simonsen, J. L., Merkulova, T. I., Litvinov, D. Y., Martensen, P. M., and Rechinsky, V. O. 1998. Functional expression of eukaryotic polypeptide chain release factors 1 and 3 by means of baculovirus/insect cells and complex formation between the factors. European Journal of Biochemistry 256:36-43. https://doi.org/10.1046/ j.1432-1327.1998.2560036.x

Frolova, L. Y., Tsivkovskii, R. Y., Sivolobova, G. F., Oparina, N. Y., Serpinsky, O. I., Blinov, V. M., Tatkov, S. I., and Kisselev, L. L. 1999. Mutations in the highly conserved GGQ motif of class 1 polypeptide release factors abolish ability of human eRF1 to trigger peptidyl-tRNA hydrolysis. RNA 5:10141020. https://doi.org/10.1017/S135583829999043X

Frolova, L., Seit-Nebi, A., and Kisselev, L. 2002. Highly conserved NIKS tetrapeptide is functionally essential in eukaryotic translation termination factor eRF1. RNA 8:129136. https://doi.org/10.1017/S1355838202013262

Gerlach, W. L. 1976. Mutational properties of supP amberochre suppressors in Saccharomyces cerevisiae. Molecular Genetics and Genomics 144:213-215. https://doi. org/10.1007/BF02428111

Grentzmann, G., Brechemier-Baey, D., Heurgue, V., Mora, L., and Buckingham, R. H. 1994. Localization and characterization of the gene encoding release factor RF3 in Escherichia coli. Proceedings of the National Academy of Sciences USA 91:5848-5852. https://doi.org/10.1073/ pnas.91.13.5848

Helsen, C. W. and Glover, J. R. 2012. Insight into molecular basis of curing of $\left[\mathrm{PSI}^{+}\right]$prion by overexpression of 104$\mathrm{kDa}$ heat shock protein (Hsp104). Journal of Biological Chemistry 287(1):542-556. https://doi.org/10.1074/jbc. M111.302869

Hatin, I., Fabret, C., Namy, O., Decatur, W. A., and Rousset, J.P. 2007. Fine-tuning of translation termination efficiency in Saccharomyces cerevisiae involves two factors in close proximity to the exit tunnel of the ribosome. Genetics 177:1527-1537. https://doi.org/10.1534/genetics.107.070771

Hatin, I., Fabret, C., Rousset, J. P., and Namy, O. 2009. Molecular dissection of translation termination mechanism identifies two new critical regions in eRF1. Nucleic Acids Research 37:1789-1798. https://doi.org/10.1093/nar/gkp012

Hawthorne, D. C. and Leupold, U. 1974. Suppressors in yeast. Current Topics in Microbiology and Immunology 64:1-47. https://doi.org/10.1007/978-3-642-65848-8_1

Himmelfarb, H. J., Maicas, E., and Friesen, J. D. 1985. Isolation of the SUP45 omnipotent suppressor gene of Saccharomyces cerevisiae and characterization of its gene product. Molecular and Cellular Biology 5:816-822. https://doi. org/10.1128/MCB.5.4.816

Hoshino, S. I., Imai, M., Mizutani, M., Kikuchi, Y., Hanaoka, F., Ui, M., and Katada, T. 1998. Molecular Cloning of a Novel Member of the Eukaryotic Polypeptide Chain-Releasing Factors (eRF) Its identification as eRF3 interacting with eRF1. Journal of Biological Chemistry 273:22254-22259. https://doi.org/10.1074/jbc.273.35.22254

Inagaki, Y., Blouin, C., Doolittle, W. F., and Roger, A. J. 2002. Convergence and constraint in eukaryotic release factor 1 (eRF1) domain 1: the evolution of stop codon specificity. Nucleic Acids Research 30:532-544. https://doi. org/10.1093/nar/30.2.532

Inagaki, Y. and Doolittle, W. F. 2001. Class I release factors in ciliates with variant genetic codes. Nucleic Acids Research 29:921-927. https://doi.org/10.1093/nar/29.4.921 
Inge-Vechtomov, S.G. 1964. Reversions to prototrophy in adenineless yeast. Vestnik Leningradskogo Universiteta 2:112-117.

Inge-Vechtomov, S. G. and Andrianova, V. M. 1970. Recessive supersuppressors in yeast. Genetika 6:103-116.

Inge-Vechtomov, S. G. and Andrianova, V. M. 1972. New type of supersuppressors in yeast. Molecular Mechanisms of Genetic Processes, Nauka, Moskow, pp. 189-195. (In Russian)

Inge-Vechtomov, S. G., Tikhodeev, O. N., and Karpova, T.S. 1988. Selective systems for obtaining recessive ribosomal suppressors in Saccharomycete yeasts. Genetika 24:1159-1165. (In Russian)

Inge-Vechtomov, S., Zhouravleva, G., and Philippe, M. 2003. Eukaryotic release factors (eRFs) history. Biology of the Cell 95:195-209. https://doi.org/10.1016/S02484900(03)00035-2

Ito-Harashima, S., Hartzog, P. E., Sinha, H., and McCusker, J. H. 2002. The tRNA-Tyr gene family of Saccharomyces cerevisiae: agenzs of phenotypic variation and position effects on mutation frequency. Genetics 161:1395-1410.

Ito, K., Ebihara, K., Uno, M., and Nakamura, Y. 1996. Conserved motifs in prokaryotic and eukaryotic polypeptide release factors: tRNA-protein mimicry hypothesis. Proceedings of the National Academy of Sciences USA 93:5443-5448. https://doi.org/10.1073/pnas.93.11.5443

Ito, K., Uno, M., and Nakamura, Y. 1998. Single amino acid substitution in prokaryote polypeptide release factor 2 permits it to terminate translation at all three stop codons. Proceedings of the National Academy of Sciences USA 95:8165-8169. https://doi.org/10.1073/pnas.95.14.8165

Ito, K., Frolova, L. Y., Seit-Nebi, A., Karamyshev, A., Kisselev, L., and Nakamura, Y. 2002. Omnipotent decoding potential resides in eukaryotic translation termination factor eRF1 of variant-code organisms and is modulated by the interactions of amino acid sequences within domain 1. Proceedings of the National Academy of Sciences USA 99:8494-8499. https://doi.org/10.1073/pnas.142690099

Kabani, M., Cosnier, B., Bousset, L., Rousset, J.P., Melki, R., and Fabret, C. 2011. A mutation within the C-terminal domain of Sup35p that affects $\left[\mathrm{PSI}^{+}\right]$prion propagation. Molecular Microbiology 81:640-658. https://doi. org/10.1111/j.1365-2958.2011.07719.x

Kobayashi, T., Funakoshi, Y., Hoshino, S. I., and Katada, T. 2004. The GTP-binding release factor eRF3 as a key mediator coupling translation termination to mRNA decay. Journal of Biological Chemistry 279:45693-45700. https://doi.org/10.1074/jbc.M405163200

Kallmeyer A. K., Keeling K. M., and Bedwell D. M. 2006. Eukaryotic release factor 1 phosphorylation by CK2 protein kinase is dynamic but has little effect on the efficiency of translation termination in Saccharomyces cerevisiae. Eukaryotic Cell 5:1378-1387. https://doi.org/10.1128/ EC.00073-06

Karamyshev, A. L., Ito, K., and Nakamura, Y. 1999. Polypeptide release factor eRF1 from Tetrahymena thermophila: cDNA cloning, purification and complex formation with yeast eRF3. FEBS Letters 457:483-488. https://doi.org/10.1016/ S0014-5793(99)01089-3

Kiktev, D., Moskalenko, S., Murina, O., Baudin-Baillieu, A., Rousset, J.P., and Zhouravleva, G. 2009. The paradox of viable sup45 STOP mutations: A necessary equilibrium between translational readthrough, activity and stability of the protein. Molecular genetics and genomics 282(1):83-96. https://doi.org/10.1007/s00438-0090447-5

Kikuchi, Y., Shimatake, H., and Kikuchi, A. 1988. A yeast gene required for the G1-to-S transition encodes a protein containing an A-kinase target site and GTPase domain. The EMBO Journal 7:1175-1182. https://doi. org/10.1002/j.1460-2075.1988.tb02928.x

Kim, O. T. P., Yura, K., Go, N., and Harumoto, T. 2005. Newly sequenced eRF1s from ciliates: the diversity of stop codon usage and the molecular surfaces that are important for stop codon interactions. Gene 346:277-286. https://doi.org/10.1016/j.gene.2004.11.046

Kim, O. T. P., Sakurai, A., Saito, K., Ito, K., Ikehara, K., and Harumoto, T. 2008. Ciliates use both variant and universal genetic codes: evidence of omnipotent eRF1s in the class Litostomatea. Gene 417:51-58. https://doi.org/10.1016/j. gene.2008.03.018

Kisselev, L. L. and Buckingham, R. H. 2000. Translational termination comes of age. Trends in Biochemical Sciences 25:561-566. https://doi.org/10.1016/S09680004(00)01669-8

Kisselev, L., Ehrenberg, M., and Frolova, L. 2003. Termination of translation: interplay of mRNA, rRNA and release factors? The EMBO Journal 22:175-182. https://doi. org/10.1093/emboj/cdg017

Kobayashi, T., Funakoshi, Y., Hoshino, S., and Katada, T. 2004. The GTP-binding Release Factor eRF3 as a Key Mediator Coupling Translation Termination to mRNA Decay. The Journal of Biological Chemistry 279:45693-45700. https:// doi.org/10.1074/jbc.M405163200

Konecki, D. R., Aune, K. C., Tate, W. P., and Caskey, T. C. 1977. Characterization of reticulocyte release factor. The Journal of Biological Chemistry 252:4514-4520.

Kong, C., Ito, K., Walsh, M. A., Wada, M., Liu, Y., Kumar, S., Barford, D, Nakamura, Y., and Song, H. 2004. Crystal structure and functional analysis of the eukaryotic class II release factor eRF3 from S. pombe. Molecular Cell 14:233245. https://doi.org/10.1016/S1097-2765(04)00206-0

Kopczynski, J. B., Raff, A. C., and Bonner, J.J. 1992. Translational readthrough at nonsense mutations in the HSF1 gene of Saccharomyces cerevisme. Molecular Genetics and Genomics 234:369-378. https://doi.org/10.1007/ BF00538696

Kushnirov, V.V., Ter-Avanesyan, M.D., Surguchov, A.P., Smirnov, V. N., and Inge-Vechtomov, S. G. 1987. Localization of possible functional domains in sup2 gene product of the yeast Saccharomyces cerevisiae. FEBS letters 215(2):257-260. https://doi.org/10.1016/00145793(87)80157-6

Kushnirov, V. V., Ter-Avanesyan, M. D., Telckov, M. V., Surguchov, A.P., Smirnov, V. N., and Inge-Vechtomov, S. G. 1988. Nucleotide sequence of the SUP2 (SUP35) gene of Saccharomyces cerevisiae. Gene 66:45-54. https://doi. org/10.1016/0378-1119(88)90223-5

Lee, C. C., Craigen, W.J., Muzny, D. M., Harlow, E., and Caskey, C. T. 1990. Cloning and expression of a mammalian peptide chain release factor with sequence similarity to tryptophanyl-tRNA synthetases. Proceedings of the National Academy of Sciences USA 87:3508-3512. https://doi. org/10.1073/pnas.87.9.3508

Liang, A., Brünen-Nieweler, C., Muramatsu, T., Kuchino, Y., Beier, H., and Heckmann, K. 2001. The ciliate Euplotes octocarinatus expresses two polypeptide release factors of the type eRF1. Gene 262:161-168. https://doi. org/10.1016/S0378-1119(00)00538-2

Liebman, J.W. and Sherman, F. 1979. Extrachromosomal $\left[\mathrm{PSI}^{+}\right]$determinant suppresses nonsense mutations in yeast. Journal of Bacteriology 139(3):1068-1071.

Liebman, S. W. and All-Robyn, J. A. 1984. A non-Mendelian factor, [eta+], causes lethality of yeast omnipotent-suppressor strains. Current Genetics 22:567-573. https://doi. org/10.1007/BF00395701 
Liu, Q. 2005. Comparative analysis of base biases around the stop codons in six eukaryotes. Biosystems 81:281-289. https://doi.org/10.1016/j.biosystems.2005.05.005

Lozupone, C. A., Knight, R. D., and Landweber, L. F. 2001. The molecular basis of nuclear genetic code change in ciliates. Current Biology 11:65-74. https://doi.org/10.1016/ S0960-9822(01)00028-8

Matveenko, A. G., Drozdova, P.B., Moskalenko, S. E., Tarasov, O.V., and Zhouravleva, G.A. 2019. Whole genome sequencing data and analyses of the underlying SUP35 transcriptional regulation for a Saccharomyces cerevisiae nonsense suppressor mutant. Data in Brief 2:103694. https://doi.org/10.1016/j.dib.2019.01.042

Merritt, G. H., Naemi, W. R., Mugnier, P., Webb, H. M., Tuite, M. F., and von der Haar, T. 2010. Decoding accuracy in eRF1 mutants and its correlation with pleiotropic quantitative traits in yeast. Nucleic Acids Research 38(16):54795492. https://doi.org/10.1093/nar/gkq338

Merkulova, T. I., Frolova, L. Y., Lazar, M., Camonis, J., and Kisselev, L. L. 1999. C-terminal domains of human translation termination factors eRF1 and eRF3 mediate their in vivo interaction. FEBS Letters 443:41-47. https://doi. org/10.1016/S0014-5793(98)01669-X

Mikuni, O., Ito, K., Moffat, J., Matsumura, K., McCaughan, K., Nobukuni, T., Tate, W., and Nakamura, Y. 1994. Identification of the $\operatorname{prfC}$ gene, which encodes peptide-chainrelease factor 3 of Escherichia coli. Proceedings of the National Academy of Sciences USA 91:5798-5802. https://doi. org/10.1073/pnas.91.13.5798

Mironova, L. N., Samsonova, M. G., Zhouravleva, G. A., Kulikov, V. N., and Soom, M.J. 1995. Reversions to respiratory competence of omnipotent sup45 suppressor mutants may be caused by secondary sup 45 mutations. Current genetics 27(3):195-200. https://doi.org/10.1007/ BF00326148

Moskalenko, S. E., Chabelskaya, S. V., Inge-Vechtomov, S. G., Philippe, M., and Zhouravleva, G. A. 2003. Viable nonsense mutants for the essential gene SUP45 of Saccharomyces cerevisiae. BMC Molecular Biology 4:2. https://doi. org/10.1186/1471-2199-4-2

Moskalenko, S.E., Zhouravleva, G.A., Soom, M.J., Chabelskaya, S.V., Volkov, K.V., Zemlyamko, O.M., Philippe, M., Mironova, L. N., and Inge-Vechtomov, S. G. 2004. Characterization of missense mutations in the SUP45 gene of Saccharomyces cerevisiae encoding translation termination factor eRF1. Russian Journal of Genetics 40(5):478-484. https://doi.org/10.1023/ B:RUGE.0000029148.58151.91

Mottagui-Tabar, S., Tuite, M. F., and Isaksson, L. A. 1998. The influence of 5'-codon context on translation termination in Saccharomyces cerevisiae. European Journal of Biochemistry 257:249-254. https://doi.org/10.1046/j.14321327.1998.2570249.x

Muramatsu, T., Heckmann, K., Kitanaka, C., and Kuchino, Y. 2001. Molecular mechanism of stop codon recognition by eRF1: a wobble hypothesis for peptide anticodons. FEBS Letters 488:105-109. https://doi.org/10.1016/ S0014-5793(00)02391-7

Nakamura, Y. and Ito, K. 2003. Making sense of mimic in translation termination. Trends in Biochemical Sciences 28:99105. https://doi.org/10.1016/S0968-0004(03)00006-9

Nakayashiki, T., Kurtzman, C.P., Edskes, H. K., and Wickner, R. B. 2005. Yeast prions [URE3] and $\left[\mathrm{PSI}^{+}\right]$are diseases. Proceedings of the National Academy of Sciences USA 102:10575-10580. https://doi.org/10.1073/ pnas.0504882102

Namy, O., Hatin, I., and Rousset, J. 2001. Impact of the six nucleotides downstream of the stop codon on transla- tion termination. EMBO Reports 2:787-793. https://doi. org/10.1093/embo-reports/kve176

Namy, O., Hatin, I., Stahl, G., Liu, H., Barnay, S., Bidou, L., and Rousset, J.-P. 2002. Gene overexpression as a tool for identifying new trans-acting factors involved in translation termination in Saccharomyces cerevisiae. Genetics 161:585-594.

Ono, B.-I., Moriga, N., Ishihara, K., Ishiguro, J., Ishino, Y., and Shinoda, S. 1984. Omnipotent suppressors effective in $\psi+$ strains of Saccharomyces cerevisiae: recessiveness and dominance. Genetics 107:219-230.

Ono, B.-I., Ishino-Arao, Y., Tanaka, M., Awano, I., and Shinoda, S. 1986. Recessive nonsense suppressors in Saccharomyces cerevisiae: action spectra, complementation groups and map positions. Genetics 114:363-374.

Paushkin, S. V., Kushnirov, V. V., Smirnov, V. N., and TerAvanesyan, M.D. 1996. Propagation of the yeast prion-like $\left[\mathrm{PSI}^{+}\right]$determinant is mediated by oligomerization of the SUP35-encoded polypeptide chain release factor. The EMBO Journal 15:3127-3134. https://doi. org/10.1002/j.1460-2075.1996.tb00675.x

Paushkin, S. V., Kushnirov, V. V., Smirnov, V. N., and Ter-Avanesyan, M. D. 1997. Interaction between yeast Sup45p (eRF1) and Sup35p (eRF3) polypeptide chain release factors: implications for prion-dependent regulation. Molecular and cellular biology 17(5):2798-2805. https://doi. org/10.1128/MCB.17.5.2798

Percudani, R., Pavesi, A., and Ottonello, S. 1997. Transfer RNA gene redundancy and translational selection in Saccharomyces cerevisiae. Journal of Molecular Biology 268:322330. https://doi.org/10.1006/jmbi.1997.0942

Poole, E. S., Brown, C. M., and Tate, W. P. 1995. The identity of the base following the stop codon determines the efficiency of in vivo translational termination in Escherichia coli. The EMBO Journal 14:151-158. https://doi. org/10.1002/j.1460-2075.1995.tb06985.x

Preis, A., Heuer, A., Barrio-Garcia, C., Hauser, A., Eyler, D. E., Berninghausen, O., Green, R., Becker, T., and Beckmann, R. 2014. Cryoelectron microscopic structures of eukaryotic translation termination complexes containing eRF1-eRF3 or eRF1-ABCE1. Cell reports 8:59-65. https://doi.org/10.1016/j.celrep.2014.04.058

Roberts, D. M., Besl, L., Oh, S.-H., Masterson, R. V., Schell, J., and Stacey, G. 1992. Expression of a calmodulin methylation mutant affects the growth and development of transgenic tobacco plants. Proceedings of the National Academy of Sciences USA 89:8394-8398. https://doi. org/10.1073/pnas.89.17.8394

Salas-Marco, J. and Bedwell, D. M. 2004. GTP hydrolysis by erf3 facilitates stop codon decoding during eukaryotic translation termination GTP hydrolysis by eRF3 facilitates stop codon decoding during eukaryotic translation termination. Molecular and Cellular Biology 24:7769-7778. https://doi.org/10.1128/MCB.24.17.7769-7778.2004

Salas-Marco, J., Fan-Minogue, H., Kallmeyer, A. K., Klobutcher, L. A., Farabaugh, P.J., and Bedwell, D. M. 2006. Distinct paths to stop codon reassignment by the variantcode organisms tetrahymena and euplotes. Molecular and Cellular Biology 26:438-447. https://doi.org/10.1128/ MCB.26.2.438-447.2006

Seit-Nebi, A., Frolova, L., Justesen, J., and Kisselev, L. 2001. Class-1 translation termination factors: invariant GGQ minidomain is essential for release activity and ribosome binding but not for stop codon recognition. Nucleic Acids Research 29(19):3982-3987. https://doi.org/10.1093/ nar/29.19.3982

Seit-Nebi, A., Frolova, L. Y., and Kisselev, L. 2002. Conversion of omnipotent translation termination factor eRF1 into 
ciliate-like UGA-only unipotent eRF1. EMBO Reports 3:881886. https://doi.org/10.1093/embo-reports/kvf178

Shapiro, R. and Vallee, B. L. 1989. Site-directed mutagenesis of histidine-13 and histidine-114 of human angiogenin. Alanine derivatives inhibit angiogenin-induced angiogenesis. Biochemistry 28:7401-7408. https://doi. org/10.1021/bi00444a038

Sherman, F. and Stewart, J. W. 1982. The Molecular Biology of the Yeast Saccharomyces: Metabolism and Gene Expression. Cold Spring Harbor Laboratory, Cold Spring Harbor, New York.

Shorter, J. and Lindquist, S. 2005. Prions as adaptive conduits of memory and inheritance. Nature Reviews Genetics 6:435. https://doi.org/10.1038/nrg1616

Schuller A. P. and Green R. 2018. Roadblocks and resolutions in eukaryotic translation. Nature Reviews Molecular Cell Biology 19:526-541. https://doi.org/10.1038/s41580-018-0011-4

Smirnov, V. N., Kreier, V. G., Lizlova, L. V, Andrianova, V. M., and Inge-Vechtomov, S.G. 1974. Recessive supersuppression in yeast. Molecular Genetics and Genomics 129:105-121. https://doi.org/10.1007/BF00268625

Smirnov, V. N., Surguchov, A. P., Fominykch, E. S., Lizlova, L. V, Saprygina, T. V., and Inge-Vechtomov, S. G. 1976. Recessive nonsense-suppression in yeast: further characterization of a defect in translation. FEBS Letters 66:12-15. https://doi.org/10.1016/0014-5793(76)80573-X

Song, H., Mugnier, P., Das, A. K., Webb, H. M., Evans, D. R., Tuite, M.F., Hemmings, B.A., and Barford, D. 2000. The crystal structure of human eukaryotic release factor eRF1-mechanism of stop codon recognition and peptidyl-tRNA hydrolysis. Cell 100:311-321. https://doi. org/10.1016/S0092-8674(00)80667-4

Song, J. M. and Liebman, S. W. 1985. Interaction of UAG suppressors and omnipotent suppressors in Saccharomyces cerevisiae. Journal of Bacteriology 161:778-780.

Stansfield, I., Grant, C. M., and Tuite, M. F. 1992. Ribosomal association of the yeast SAL4 (SUP45) gene product: implications for its role in translation fidelity and termination. Molecular Microbiology 6:3469-3478. https://doi. org/10.1111/j.1365-2958.1992.tb01782.x

Stansfield, I. and Tuite, M. F. 1994. Polypeptide chain termination in Saccharomyces cerevisiae. Current Genetics 25:385395. https://doi.org/10.1007/BF00351776

Stansfield, I., Jones, K. M., Kushnirov, V. V., Dagkesamanskaya, A. R., Poznyakovski, A. I., Paushkin, S. V., Nierras, C. R., Cox, B. S., Ter-Avanesyan, M. D., and Tuite, M. F. 1995a. The products of the SUP45 (eRF1) and SUP35 genes interact to mediate translation termination in Saccharomyces cerevisiae. The EMBO Journal 14:4365-4373. https://doi. org/10.1002/j.1460-2075.1995.tb00111.x

Stansfield, I., Akhmaloka, and Tuite, M. F. 1995b. A mutant allele of the SUP45 (SAL4) gene of Saccharomyces cerevisiae shows temperature-dependent allosuppressor and omnipotent suppressor phenotypes. Current Genetics 27:417-426. https://doi.org/10.1007/BF00311210

Stansfield, I., Eurwilaichitr, L., Akhmaloka, and Tuite, M. F. 1996. Depletion in the levels of the release factor eRF1 causes a reduction in the efficiency of translation termination in yeast. Molecular Microbiology 20:1135-1143. https://doi. org/10.1111/j.1365-2958.1996.tb02634.x

Studte, P., Zink, S., Jablonowski, D., Bär, C., von der Haar, T., Tuite, M. F., and Schaffrath, R. 2008. tRNA and protein methylase complexes mediate zymocin toxicity in yeast. Molecular Microbiology 69:1266-1277. https://doi. org/10.1111/j.1365-2958.2008.06358.x

Surguchov, A.P., Berestetskaya, Y. V., Fominykch, E.S., Pospelova, E. M., Smirnov, V. N., Ter-Avanesyan, M. D., and Inge-Vechtomov, S. G. 1980. Recessive suppression in yeast Saccharomyces cerevisiae is mediated by a ribosomal mutation. FEBS Letters 111:175-178. https://doi. org/10.1016/0014-5793(80)80786-1

Surguchev, A.P., Piepersberg, W., Smirnov, V. N., Ter-Avanesian, M. D., and Inge-Vechtomov, S. G. 1983. Cloning of the gene sup 1 of Saccharomyces cerevisiae yeasts. Doklad Akademii Nauk SSSR 272:987.

Tate, W. P. and Mannering, S. A. 1996. Three, four or more: the translational stop signal at length. Molecular Microbiology 21:213-219. https://doi.org/10.1046/j.13652958.1996.6391352.x

Telkov, M. V, Surguchev, A.P., Dagkesamanskaya, A. R., and Avanesyan, M. D. 1986. Isolation of a chromosomal DNA fragment containing sup2 gene of the yeast S. cerevisiae. Genetika 22:17-25.

Ter-Avanesyan, M.D., Kushnirov, V.V., Dagkesamanskaya, A. R., Didichenko, S. A., Chernoff, Y. O., Inge-Vechtomov, S. G., and Smirnov, V. N. 1993. Deletion analysis of the SUP35 gene of the yeast Saccharomyces cerevisiae reveals two non-overlapping functional regions in the encoded protein. Molecular Microbiology 7:683-692. https://doi.org/10.1111/j.1365-2958.1993.tb01159.x

Ter-Avanesyan, M.D., Dagkesamanskaya, A. R., Kushnirov, V. V., and Smirnov, V. N. 1994. The SUP35 omnipotent suppressor gene is involved in the maintenance of the non-Mendelian determinant $\left[\mathrm{PSI}^{+}\right]$in the yeast Saccharomyces cerevisiae. Genetics 137:671-676.

Tieg B. and Krebber H. 2013. Dbp5 - from nuclear export to translation. Biochimica et Biophysica Acta (BBA)-Gene Regulatory Mechanisms 1829:791-798. https://doi. org/10.1016/j.bbagrm.2012.10.010

Tork, S., Hatin, I., Rousset, J., and Fabret, C. 2004. The major 5 -determinant in stop codon read-through involves two adjacent adenines. Nucleic Acids Research 32:415-421. https://doi.org/10.1093/nar/gkh201

True, H. L. and Lindquist, S. L. 2000. A yeast prion provides a mechanism for genetic variation and phenotypic diversity. Nature 407:477. https://doi.org/10.1038/35035005

True, H. L., Berlin, I., and Lindquist, S. L. 2004. Epigenetic regulation of translation reveals hidden genetic variation to produce complex traits. Nature 431:184. https://doi. org/10.1038/nature02885

Uptain, S. M., Sawicki, G. J., Caughey, B., and Lindquist, S. 2001. Strains of $\left[\mathrm{PSI}^{+}\right]$are distinguished by their efficiencies of prion-mediated conformational conversion. The EMBO Journal 20:6236-6245. https://doi.org/10.1093/emboj/20.22.6236

Valouev, I.A., Urakov, V. N., Kochneva-Pervukhova, N. V., Smirnov, V. N., and Ter-Avanesyan, M. D. 2004. Translation termination factors function outside of translation: yeast eRF1 interacts with myosin light chain, Mlc1p, to effect cytokinesis. Molecular Microbiology 53(2):687-696. https://doi.org/10.1111/j.1365-2958.2004.04157.x

Volkov, K. V., Kurishko, K., Inge-Vechtomov, S. G., and Mironova, L. N. 2000. Polymorphism of the SUP35 gene and its product in the Saccharomyces cerevisiae yeasts. Genetika 36:155-158.

Volkov, K. V., Aksenova, A. Y., Soom, M.J., Osipov, K. V., Svitin, A. V., Kurischko, C., and Mironova, L. N. 2002. Novel non-Mendelian determinant involved in the control of translation accuracy in Saccharomyces cerevisiae. Genetics 160:25-36.

Volkov, K.V., Osipov, K. V., Valouev, I.A., Inge-Vechtomov, S. G., and Mironova, L. N. 2007. N-terminal extension of Saccharomyces cerevisiae translation termination factor eRF3 inuences the suppression efficiency of sup35 mutations. FEMS Yeast Research 7:1-10. https:// doi.org/10.1111/j.1567-1364.2006.00176.x 
Wickner, R. B. 1994. [URE3] as an altered URE2 protein: evidence for a prion analog in Saccharomyces cerevisiae. Science 264:566-569. https://doi.org/10.1126/science.7909170

Wickner, R. B., Masison, D. C., and Edskes, H. K. 1995. $\left[P S I^{+}\right]$ and [URE3] as yeast prions. Yeast 11:1671-1685. https:// doi.org/10.1002/yea.320111609

Wilson, P.G. and Culbertson, M.R. 1988. SUF12 suppressor protein of yeast. A fusion protein related to the EF-1 family of elongation factors. Journal of Molecular Biology 199:559-573. https://doi.org/10.1016/00222836(88)90301-4

Zavialov, A. V., Buckingham, R. H., and Ehrenberg, M. 2001. A posttermination ribosomal complex is the guanine nucleotide exchange factor for peptide release factor RF3. Cell 107:115-124. https://doi.org/10.1016/S00928674(01)00508-6
Zhou, P. 1999. The yeast non-Mendelian factor $\left[E T A^{+}\right]$is a variant of $\left[\mathrm{PSI}^{+}\right]$, a prion-like form of release factor eRF3. The EMBO Journal 18:1182-1191. https://doi.org/10.1093/ emboj/18.5.1182

Zhouravleva, G., Frolova, L. Y., Goff, X. Le, Guellec, R. Le, IngeVechtomov, S., Kisselev, L., and Philippe, M. 1995. Termination of translation in eukaryotes is governed by two interacting polypeptide chain release factors, eRF1 and eRF3. The EMBO Journal 14:4065-4072. https://doi. org/10.1002/j.1460-2075.1995.tb00078.x

Zhouravleva, G.A., Moskalenko, S.E., Murina, O.A., and Inge-Vechtomov, S. G. 2007. Viable nonsense mutants for the SUP45 gene in the yeast Saccharomyces cerevisiae are lethal at increased temperature. Russian Journal of Genetics 43:1139-1146. https://doi.org/10.1134/ S1022795407100079 